\title{
La Comarca de Tudela', esquema de comprensión de un desarrollo regional en la época Prerromana y Romana
}

\author{
JuAn José Sayas ABEngochea \\ UNED
}

1. Quien aborde la tarea de realizar un estudio sobre las tierras y gentes de Navarra en la Antigüedad tropezará de inmediato con corrientes historiográficas relativas a la debatida cuestión de la antiquísima identidad del pueblo vasco ${ }^{2}$. La identificación de los elementos étnico-culturales característicos que definen la unidad e identidad de esse pueblo, y la espe-

En la realización de este trabajo hemos disfrutado de una ayuda a la investigación del CICYT (referencia BHA 2001-1397)

1 Ponemos de manifiesto como indicación inicial la inconveniencia metodológica en la que se incurriría si se realizase mecánicamente un reducionismo entre ámbito histórico-arqueológico de la Ribera de Navarra y el ámbito arqueológico-histórico de la comarca tudelana. "Ribera de Navarra» es un término político-administrativo circunscrito a la Comunidad Foral de Navarra. "Comarca de Tudela" es, por el contrario, una expresión que carece de entidad político-administrativa. Por esa misma indefinición resulta más apropiada para acoger en su seno las estrechas relaciones que a lo largo del tiempo sostuvo con tierras riojanas y aragonesas próximas. Es indudable que el Ebro constituye un factor de unidad, pero también un obstáculo importante, especialmente en época prerromana, que dificulta las comunicaciones fluidas y relaciones estrechas entre las poblaciones de ambas orillas. Así, aunque es evidente que podremos llamar vasconas a las poblaciones asentadas en tierras cascantinas y a las que pervivieron en el Cerro de Santa Barbara de Tudela, en la orilla derecha del Ebro, y que lo mismo podemos decir de las poblaciones de la vega del río Ega, correspondiente a la zona de Ribera, o de las poblaciones asentadas en el término tudelano de Marijuán, lindando con las Bardenas o las de San Gregorio de Tudela lindando con el municipio de Cabanillas, realmente las relaciones entre ellas distarían mucho de ser fluidas. Sin puentes en época prerromana, o con un puente relativamente lejos en época romana, sin presas que retuvieran el agua y con sospecha de un caudal muy grande a lo largo de la mayor parte del año, va de suyo el pensar como muy razonable que relaciones entre las poblaciones del Cerro de Santa Bárbara de Tudela y las de Marijuán y San Gregorio, tambièn de Tudela, eran muy pocas. En cualquier caso, mucho más infrecuentes que las que pudiera mantener la población de Santa Bárbara con los habitantes de las tierras de Tarazona y Mallén, por citar tierras que no eran ni se calificarán posteriormente como vasconas. Por razones de proximidad y facilidad de desplazamientos la gentes de la comarca tudelana de la orilla derecha del Ebro fueron desde época temprana muy receptivas a las influencias venidas a través de las vías del Ebro. Esto no es óbice para que utilicemos datos de asentamientos situados en la orilla izquierda del Ebro.

2 Conviene señalar que los términos vasco y vascón/vascones no son intercambiables desde el punto de vista metodológico. No hay reducción posible entre vasco y vascón. Vasco es un término moderno, de sentido distinto y más amplio. Las expresiones "etnia vasca" o "pueblo vasco" y "pais vasco" son expresiones modernas, útiles para designar, por una parte, al pueblo que desde la época prehistórica se supone que tenia rasgos étnico-culturales especificos y, por otra, el marco geográfico y el pueblo que ocupa actualmente ese territorio. Vascones, por el contrario, se refiere a una etnia concreta, que ocupaba un marco geográfico más reducido y no plenamente coincidente con el territorio vasco actual. No obstante, las expresiones "etnia vasca" 0 "pueblo vasco" y "país vasco" Hevan en su composición el término "vasco", un vocablo moderno derivado del término latino Vascones, nombre de una etnia testimoniada en las fuentes literarias, cuyo singular Vasco se documenta como nombre en Silio Itálico (III, 358: aut Vasco) y en Prudencio como adjetivo (Per., II, 537: Vasco Hiberus). 
cificación e insistencia en la ocupación continuada desde época remota hasta la actualidad por parte de dicho pueblo de casi el mismo espacio geográfico son cuestiones complejas que desde diversos ámbitos del poder han sido tratadas, entre otros, por T. Aranzadi y J. M. Barandiarán, I. Barandiarán, E. Vallespí, J. M. Basabe, M. Fuste, J. Corominas, K. Mitxelena, J. Untermann, J. Gorrochategui, J. Caro Baroja y J. J. Sayas.

1.1. Sin duda alguna los criterios de valoración de una identidad y unidad vascona antiquísima van más allá y son de entidad diferente de los datos y rasgos étnico-culturales que el historiador puede deducir del análisis de los textos escritos. El contenido del historiador es estudiar y analizar la sociedad que reflejan los testimonios escritos, una vez que dichos testimonios han estado sometidos a la criba de la crítica textual, que es la que garantiza y determina la objetividad y fiabilidad de los mismos. Su cometido, por tanto, no es el estudio de la prehistoria y de la protohistoria, sino de la realidad que reflejan los textos. Por eso, cuando el historiador, por imperiosa conveniencia de prestar atención a los puntos y bases de partida a partir de los cuales una sociedad comienza su andadura histórica, tiene en cuenta elementos culturales pertenecientes a época prehistórica y protohistórica, debe guiarse en esta incursión fuera de su disciplina a lo que los arqueólogos han establecido al respecto.

Pero, en este sentido, es evidente que los arqueólogos también se ven condicionados por los métodos empleados en el estudio de sus materias, métodos por lo general restringidos a su propia dimensión heurística. Por lo tanto no puede perderse de vista que los objetos que los arqueólogos obtienen y los restos constructivos que detectan son elementos pertenecientes a la cultura material cuya operatividad y participación en el conocimiento y reconstrucción de las estructuras étnico-culturales y la percepción de la esencia de las instituciones políticas, sociales y religiosas de un pueblo antiguo es escasa y no decisiva. Con todo, para el historiador estos datos resultan de gran utilidad, pues le ayudan a comprender el tipo y dimensión de los cambios que se producen en una comarca determinada, los procesos de aculturación material que experimentan sus habitantes y los elementos de unidad o de diferenciación que sostienen con los pobladores de las zonas adyacentes. De esta manera, la persistencia en una zona de instrumentos y materiales concretos, la reiterada repetición de los mismos, añadida a las diferencias que ofrecen respecto a los instrumentos y materiales aparecidos en otras zonas, es lo que lleva a los arqueólogos a pensar que las comunidades que los aportan mantienen entre ellas lazos de unidad y de identidad.

Pero esto no es suficiente, y por eso no es inusual que el arqueólogo, pese a cualquier intento voluntarista, no encuentre los condiciones adecuadas para poder identificar los rasgos materiales "propios» de una etnia histórica, que, por supuesto, va más allá de la evidencia estrictamente material. Pero los datos proporcionados por el arqueólogo, o en su caso, el modelo de 
ocupación territoria establecido por él para la época protohistórica son de gran utilidad para el historiador, pues puede confrontarlos con los datos conocidos por las fuentes literarias.

1.2. En este sentido, los arqueólogos, para el periodo Eneolítico-Bronce, constatan en tierras navarras dos formas distintas de asentamientos: en cuevas y al aire libre. La Ribera de Navarra es la que ofrece los talleres de silex al aire libre, quizás por falta de cuevas apropiadas. Y sobre ese telón de fondo general hay que situar los datos arqueológicos provenientes de excavaciones y proyecciones arqueológicas y los hallazgos fortuitos ${ }^{3}$. Son materiales de escasa espectacularidad, pero de importante interés históri$\mathrm{co}$, pues permiten identificar una serie de yacimientos al aire libre que ponen de manifiesto que las tierras de la comarca de Tudela estaban ya relativamente pobladas durante el periodo Eneolítico-Bronce. Pero de todos estos vestigios y objetos, sólo los restos de algún yacimiento ofrecen difusas huellas de cabañas. No parece, sin embargo, que esta dualidad de formas de asentamiento en cuevas o al aire libre según la comarca navarra que se considere exteriorice dos culturas diferentes. Respondía más bien, como parece razonable, a dos aspectos de una misma cultura de trashumancia, pudiendo deducirse de ello que las poblaciones de la comarca objeto de estudio estaban inmersas durante la época considerada en un horizonte cultural común.

2. No es una cuestión que carezca de importancia desde el momento en que no son pocos los investigadores que sostienen que la configuración de

\footnotetext{
${ }_{3}$ Hallazgos de objetos se conocían en el término municipal de Tudela (Portillo de Tudela, Barranco de Valdelafuente), en el de Corella (Valles del Muro, Yeco de Balbiné, Torrecilla, Portillo de Alfaro, Ontizar, Nevera, Las Navas, Cabezo de la Baraja), en el de Castejón (Cerro de la Brea, Cerro del Castillo, Cerro del Soto), en el de Cascante, Monteagudo, Fontellas, Buñuel, y en Las Bardenas Reales. Algunos de estos hallazgos se recogen en revistas científicas. Ver J. Maluquer de Motes, "Talleres de silex, al aire libre, del Norte de Aragón, P. V. 58, 1955, pp. 9-23; M. Llongueras y L. Monreal, "Hallazgos de material lítico en la Ribera Navarra del Ebro" en VII CNA, Zaragoza, 1962, pp. 127-132 para el yacimiento del término de Tudela y los tres de los alrededores de Castejón; E. Vallespi, "talleres de silex al aire libre en el País Vasco meridional", EAA, 3 1968, pp. 7-27; Ma A. Beguiristáin, "Los yacimientos de habitación durante el Neolitico y Edad de Bronce en el Alto Valle del Ebro", Trabajos de Arqueología Navarra 3, 1982, pp. 59-156). Huellas de talleres de silex se han localizado en la Bardena de Caparroso. Abundantes materiales de los talleres de silex y objetos correspondientes a la edad del bronce se encontraron en las prospecciones realizadas en el 1993 en los municipios de Valtierra, Cabanillas y Fustiñana. Las efectuadas en Las Bardenas Reales, una zona ecológica peculiar, han proporcionado un volumen importante de materiales de los talleres de silex como hachas pulimentadas, piedras de silex talladas, etc. Se han detectado más de 80 yacimientos, destacando los yacimientos - con más de una hectárea- de Monte Aguilar y Pisquerra. Hay que significar el yacimiento tudelano de la Edad del Bronce del término Marijuán, en la orilla izquierda del Ebro lindando a las Bardenas. En tierras de la orilla derecha del Ebro se han realizado recientes prospecciones en los municipios de Cortes, Buñuel, Ribaforada, Fontellas. Esta zona de la orilla derecha del Ebro, a la que pertenecen las tierras del valle del Queiles y del Alhama, han proporcionado los materiales más antiguos, como los restos líticos de época paleolítica recogidos en tos términos de La Albea y la Balsa del Pulguer, los objetos de talleres de silex obtenidos en yacimientos localizados en las proximidades de Cascante, en Castejón, Tudela, Fontellas, localidad esta última que cuenta con otro yacimiento de la Edad de Bronce que conserva huellas de restos de cabañas. Del Cerro de la Mesa, en Ablitas, se han recogido fragmentos de cerámica.
} 
la etnia vasca en sus elementos básicos antropológicos y culturales acontece inmediatamente después de la fase cronológica indicada, a mediados del II milenio a. d C. ${ }^{4}$, y alcanza, según se dice, casi todo el suelo provincial. Esta alusión al ámbito territorial se hace de una manera muy general y como una forma de insistencia en la importancia del hecho, pues es evidente que todos los investigadores están de acuerdo de que determinar con precisión las tierras a las que alcanza con plenitud la configuración de la «etnia vasca» resulta una tarea harto difícil.

De hecho el propio término de etnia, que deriva de la palabra griega ethnos (latín gens), se caracteriza por una cómoda ambigüedad. Pese a ello, algunos factores como hábitat, tipo de asentamiento, comunidad económica, comunidad de origen, conciencia de unidad, etnónimo, etc., deberían entrar en la definición y constatarse inequívocamente en el estudio de un pueblo, pues algunos de esos factores resultan indispensables para distinguir unas etnias de otras. Un "pueblo" o de una "etnia" concreta asentada en un territorio determinado debiera exteriorizar de forma específica y poner de manifiesto claramente algunos de esos estos rasgos socioculturales peculiares distintos de los que ofrecen otros pueblos. Pero puesto que hasta la fecha no hay posibilidad de precisar con datos inequivocos la lengua (que es el elemento espiritual por antonomasia de una etnia o de un pueblo) que se hablaba en las tierras adyacentes de ambas orillas del Ebro, sería de sumo interés preguntarse y tratar de precisar si se cuenta con algún rasgo o rasgos-fósiles característicos (cerámica, hábitat, poblamiento) que sea común o comunes a las poblaciones de la Montaña, de la zona Media de Navarra y de La Ribera, o si, por el contrario, lo que en realidad se percibe en el conjunto territorial navarro desde el punto de vista arqueológico son diferencias internas regionales: zona de dólmenes y en cierta manera también de asentamientos en cueva, por un lado , $y$, por otro, asentamiento al aire libre. $Y$ teniendo presente esta realidad arqueológica cabe preguntarse sobre cuál pudiera ser el rasgo peculiar arqueológico que pudiera asumirse como común a todas o a casi todas las poblaciones que configurarán la etnia vasca en el período indicado. En definitiva, ¿hay algún rasgo arqueológico específicamente vascón común a todas las poblaciones del solar navarro?

2.1. Precisamente estas preguntas resultan pertinentes con carácter previo para aquellos momentos que constituyen la antesala cronológica de la llegada de gentes centroeuropeas, pues con la arribada de estas gentes y sus aportes culturales la población del territorio navarro inició un camino de profundos cambios y transformaciones poblacionales y culturales que provocaron un aumento y reforzamiento significativo de las diferencias regionales

4 Ver al respecto I. Barandiarán y E. Vallespí, Prehistoria de Navarra, Pamplona, 1974, p. 222. También las agudas reflexiones de $\mathrm{l}$. Barandiarán en «Presupuestos culturales a la prehistoria de los pueblos del Pirineo occidental y zonas aledañas", Studia Palaeohispanica, Actas del IV coloquio sobre lenguas y culturas paleohispánicas I, Victoriaco Vasconum, 1987, pp. 258-259. 
y comarcales. En los altos valles, poblados con relativa densidad en la Edad del Bronce ${ }^{5}$ estos cambios apenas se dejan sentir. Sin embargo son importantes por debajo de la línea imaginaria Lumbier-Pamplona, especialmente en las tierras del Valle Medio del Ebro y de sus afluentes. Los investigadores catalogan más de 80 yacimientos, unos excavados y otros simplemente prospectados. Varios de estos poblados se encuentran en tierras próximas al Ebro, entre ellos los del Cerro de la Cruz de Cortes, el Cerro de Santa Bárbara de Tudela, El Castillar de Mendavia, Partelaleña en el Redal (Rioja), amén de las importantes e interesantes necrópolis de Cortes de Navarra, Valtierra, Arguedas y el Castillo de Castejón ${ }^{6}$.

2.2. Los datos arqueológicos de la comarca de Tudela permiten hacer un balance de las pautas generales seguidas en la ocupación territorial, pero cualitativamente son insuficientes para conocer la génesis particular y la identidad precisa de las gentes que componian cada uno de esos poblados. Es altamente factible que la intrusión en la comarca de poblaciones foráneas que estaban más evolucionadas que las nativas desde el punto militar y cultural tuviera como consecuencia su asentamiento en espacios vacíos

5 En la zona pírenaica la cuitura material y la forma de ocupar el territorio apenas sufre alteraciones. Las tierras estaban ocupadas por gentes nativas, que dejan testimonio arqueológico de su presencia en cuevas y en los llamados circulos de piedra, en donde se practicó el rito de la incineración. Algunos de estos cromlechs se datan en la Edad del Hierro. A este respecto ver las opiniones de J. M. BARANDIARÁN, "Contribución al estudio de los cromlechs pirenaicos" en Homenaje a Urquijo, V, San Sebastián, pp. 197212; El hombre prehistórico en el Pais Vasco, Buenos Aires, p. 175. Sobre la difusión de estos monumentos por las dos vertientes pirenaicas y su finalidad como sepulturas de incineración, ver J. Blot, “Nouveaux vestiges mégalithiques en Pays Basque (VII).Contribution à la Protohistoire en Pays Basque", Bull. du Musée Basque de Bayonne, 64, 1974, pp. 66-100. M. T. AnDRÉs, "Los cromlechs pirenaicos", Els Pobles preromans del Pirineu, Puigcerdá, 109-117, se plantea la cuestión de su posible origen celta.

6 Una visión de conjunto de estos yacimientos puede verse en J. J. SAYAS ABENGOCHEA, El poblamiento romano en el área de los Vascones", Veleia, 1, 289-310; "Indoeuropeos y Vascones en territorio vascón" en Studia Palaeohispanica. Actas del IV Coloquio Internacional sobre Lenguas y Culturas Paleohispánicas,(Vitoria, desde el 6 al 10 de Mayo 1985), Vitoriaco Vasconum, 399-420 y, especialmente, en A. Castiella, La Edad del Hierro en Navarra y Rioja, Pamplona, 1977; "Nuevos yacimientos protohistóricos en Navarra», Trabajos de Arqueología de Navarra 5, 1985, pp. 133-174; «Nuevos datos sobre la Protohistoria de Navarra" en Actas del Primer Congreso General de Historia de Navarra. Anejo 7 de Príncipe de Viana. Comunicaciones, Pamplona, 1986, pp. 229-238.

Limitándonos a la Ribera, en el valle del Aragón, además del poblado de la Edad del Hierro sobre el que se asentó la Cara romana, se han detectado materiales de la Edad del Hierro en el yacimiento de El Congosto de Carcastillo, en los de La Huerta y El Morro de la Barca en Mélida.

En tierras de la zona del Arga hay noticias de que se obtuvieron objetos en un yacimiento de Marcilla y en la Atalaya de Peralta.

En tierras próximas al Ebro, empezando por la margen izquierda y de occidente a oriente cabe mencionar los diversos asentamientos, probabiemente berones, pertenecientes a la Custodia de Viana (Navarra), los asentamientos de El Castillar y La Atalaya de Los Arcos (Navarra), el poblado del Castillar de Mendavia (Navarra), el yacimiento de El Castillar de Lodosa (Navarra), los poblados del Castillo de Valtierra (Navarra) y de El Castejón de Arguedas (Navarra), el asentamiento de San Gregorio (Tudela, Navarra) y los diversos poblados de Las Bardenas Reales

En la margen derecha y desde occidente a oriente se hallan los asentamientos - Sorbán, La Torrecilla, El Valladar, Los Arbolazos, Carnpobajo- próximos a Calahorra La Rioja), Cerro del Castillo de Castejón (Navarra), el poblado del Cerro de Santa Bárbara (Tudela, Navarra), el yacimiento de El Castellar de Fontellas (Navarra), los dos yacimientos en cercania a Cascante (Navarra), el yacimiento de el Molino en Monteagudo (Navarra), el poblado conocido como Peña del Saco de Fitero (territorio riojano) y El Cerro de la Mesa de Ablitas (Navarra). 
acaparando las mejores tierras. Cabe pensar que esta no sería la única situación. Es normal que se produjera el desplazamiento de la población autóctona hacia otros lugares y que aconteciera en algunos lugares la reabsorción de la población autóctona en la foránea o la foránea en la nativa, incluso la simple recepción de influjos culturales exteriores por parte de la población indigena, sin aportación poblacional foránea. Ciertamente, algunas de estas situaciones se perciben en algunos de los yacimientos excavados en mayor o menor extensión. Así las excavaciones de los poblados de Cortes de Navarra, de Mendavia y el de Partelaleña (El Redal, La Rioja) traducen una continuidad del Bronce Final-Edad del Hierro ${ }^{7}$. En otras zonas la remodelación y reordenación del territorio estuvo acompañada del abandono de yacimientos de la Edad del Bronce, mientras que en otras las tierras pasaron a estar ocupadas por poblados de la Edad del Hierro ${ }^{8}$.

Las huellas de construcciones y los objetos procedentes de estos poblados se atribuyen decididamente a los indoeuropeos, en cuanto que ellos son los portadores o difusores de esos influjos culturales entre los nativos. Pero precisar el alcance y repercusión de esos influjos étnicos y culturales foráneos sobre un territorio provincial del que se suponía que disfrutaba previamente de una cierta uniformidad étnica y cultural, no resulta tarea fácil. Para la comarca tudelana esta tarea resulta más compleja y confusa, pues mientras en los territorios de la Navarra Media el registro en época romana de epígrafes teónimos y antropónimos de raigambre vascona permiten retrotraer para la época del Bronce Final e inicios de la Edad del Hierro la existencia y pervivencia de gentes que usaban el vasco antiguo, tal situación no se produce en la comarca tudelana. No se dispone de tales testimonios, de-

La excavaciones efectuadas en el poblado de Cortes de Navarra dadas a conocer en el 1985 por J. Maluquer, dejaban entrever un arranque del poblado en la Edad del Bronce, algo que confirmaron las excavaciones posteriores, ver J. Maluquera, T. Garcia Alonso y Munilla Cabrillana, "Alto de la Cruz, Cortes de Navarra. Campañas 1986-87", Trabajos de Arqueología de Navarra, Pamplona, 1988 y "Alto de la Cruz. Cortes de Navarra. Campaña 1986-1988", Trabajos de Arqueología de Navarra, 9, Pamplona, 1990. A su ver A. CAStIElla, «EI Castillar de Mendavia. Poblado protohistórico", Trabajos de Arqueología de Navarra, 4. Pamplona, 1985, pp. 65-143, aquí pp. 65-9, en su excavación del yacimiento de El Castillar de Mendavia llegó a un nivel en el que habia evidencias de un primer asentamiento (Poblado I) que correspondia al Bronce Final y que evolucionaba y enlazaba a to largo de la Edad del Hierro con los poblados II y III. Y para conocer en La Rioja el arranque de algunos poblados en el Bronce Final, ver A. Álvarez C. L. PEREZ, La cerámica excisa de la Primera Edad del Hierro en el valle Alto y Medio del Ebro, Logroño, 1987, p. 68.

8 El contacto de poblaciones étnica y culturalmente diferentes en un mismo territorio se considera en J. J. Sayas Abengochea, El poblamiento romano en el área de los Vascones", Veleia, 1, 289-310; "indoeuropeos y Vascones en territorio vascón" en Studia Palaeohispanica. Actas del IV Coloquio Internacional sobre Lenguas y Culturas Paleohispánicas,(Vitoria, desde el 6 al 10 de Mayo 1985), Vitoriaco Vasconum, 399-420. Por otra parte, las excavaciones y prospecciones arqueológicas efectuadas en yacimientos de Las Bardenas Reales, una zona ecológicamente muy delimitada y definida, han puesto de manifiesto que la presencia de estas gentes foráneas condujo a un relativo abandono de los asentamientos. Se cifra esa desocupación en el descenso del número de los yacimientos por desplazamiento o concentración de población. Se constata también que los asentamientos más importantes se localizan en la zona del Ebro. Ver al respecto J. SESMA y $M^{a} L$. GARCiA, «La ocupación desde el Bronce Antiguo a la Edad Media en las Bardenas Reates de Navarra",Cuadernos de Arqueología de la Universidad de Navarra 2 , 1993, pp. 97-218; “Monte Aguilar (Bardenas Reales de Navarra) Campañas de 1990-1991". Trabajos de Arqueología de Navarra, 11, 1993-4, pp. 276-279. 
bido quizás al material pétreo adecuado utilizado para realizar inscripciones que no abunda en esa zona navarra.

La comarca tudelana ha proporcionado muy pocos epígrafes y el material lingüístico que aporta no permite inferir con seguridad cuál pudiera ser la adscripción étnico-cultural de sus pobladores en momentos inmediatamente anteriores a la presencia indoeuropea. Que no se hayan encontrado todavía en la zona datos de raigambre vascona que permitan deducir inequívocamente que esa era la adscripción étnico-cultural de la comarca no permite concluir que queden cerradas con ello las puertas a esa posibilidad. Sólo indica que la investigación histórica y lingüística, que se alimenta de datos escritos fiables y veraces, no puede decir al respecto gran cosa, dada la calidad de los datos que tiene a disposición; mucho menos retrotraerlos a un momento cronológico anterior.

Pero en cualquier caso, la situación lingüistica resultaría muy similar en el caso de que a modo de hipótesis se partiera del supuesto de que la zona en cuestión tuvo, con anterioridad a la presencia de los indoeuropeos, de una adscripción étnico-cultural vascona, pero luego fue objeto de una profunda devasconización a cargo de los indoeuropeos. Naturalmente se trata de una hipótesis, incluso alguien pudiera calificarla de mera y frívola hipótesis, pero es la ausencia de datos lingüísticos en una dirección determinada o la existencia de otros posteriores en sentido contrario lo que hace que la inclinación hacia la suposición o negación de la adscripción vascona de la comarca tudelana carezca de entidad suficiente. Así, quienes se inclinen por la adscripción vascona de la zona se enfrentan en esta suposición con el hecho de que los datos disponibles en la comarca tudelana anteriores a la presencia indoeuropea son de carácter material y no lingüístico, elemento este último de suma importancia para establecer diferenciaciones étnicas, pues es usual que si se habla celtibero o vasco antiguo se sea celtibero o de estirpe vasca, aunque ciertamente etnia y lengua no siempre coincidan. Por otra parte, ninguno de los datos de cultura material encontrados en la comarca tudelana asume el carácter de elemento-fósil inequívocamente vascón, ante cuya presencia o ausencia pudiera concluirse con certeza que la zona era o no vascona. En este sentido, no puede afirmarse que los datos registrados en la comarca de Tudela puedan considerarse más vascones o menos vascones desde el punto de vista de la cultura material que los obtenidos de la amplia cuenca de Pamplona y en la zona media de Navarra, en las que sabemos que se habla el vasco antiguo en razón a teónimos y antropónimos de apariencia vasca recogidos en epígrafes latinos.

Quienes niegan la adscripción vascona de esa comarca cuentan real o aparentemente con datos de mayor entidad en el sentido de que cuando la escritura, elemento clasificador de primer orden, hace acto de presencia en esa comarca en época romana los escasos testimonios lingüísticos aportados son de indole ibérica y celtibérica. Eso es cierto, pero también es verdad que cuando tal cosa sucede la comarca tudelana llevaba siglos y siglos de profunda indoeuropeización, celtiberización e iberización, suficiente, con 
holgura, para que quedase poco de la cultura vascona anterior, si es que la hubo en la zona. No se puede ser tajante a este respecto. El hecho lingüístico no es un fenómeno aislado en si, lleva adheridas otras cuestiones e interrogantes como los de la persistencia, resistencia o reabsorción étnico-cultural de la población preindoeuropea de la zona. $¿$ O es que se dispone de argumentos suficientes para pensar en términos de un barrido o de una sustitución poblacional? Parece que no es así y el problema a dilucidar sigue centrado en el esclarecimiento de cuál pudiera ser la situación étnicocultural de la comarca con anterioridad a la llegada de los indoeuropeos.

3. Los indoeuropeos crearon los fermentos precisos para transformar profundamente la forma de ocupar el territorio comarcal territorial que en algunos casos estuvo acompañada de la desaparición de los asentamientos anteriores de la Edad del Bronce. Los restos exhumados en las excavaciones, los obtenidos merced a sistemáticas prospecciones arqueológicas y los hallazgos fortuitos ponen de manifiesto la densidad de poblados aparecidos. Pero este proceso de ocupación territorial, que estuvo animado de un gran dinamismo, se prolongó a lo largo del amplio período de la Edad del Hierro. $Y$ en ese período los cambios y las alteraciones han sido constantes, aunque en algunos casos y lugares estos cambios y alteraciones no se puedan precisar en sus componentes básicos, en razón a la poca fiabilidad que refrenda el carácter aleatorio y poco riguroso que acompaña la disponibilidad de algunos datos arqueológicos que sirven de base para el conocimiento de muchos asentamientos determinados. De esta forma, sólo de algunos asentamientos como los poblados del Alto de la Cruz y el de El Castillar de Mendavia, en los que se identifican estructuras protourbanas y huellas de casas, se puede afirmar que su vida se apaga en el tránsito de la Edad del Hierro I a la II, gracias a que la secuencia arqueológica se conoce muy bien y está bien establecida. De otros poblados puede afirmarse, por razones similares, que tienen su arranque en la Edad del Hierro II, como sucede en el poblado de la Peña del Saco de Fitero. Por el contrario, la ausencia de excavaciones - la escasez de datos arqueológicos no permiten sacar conclusiones muy precisas en lo que respecta a la mayoría de los restantes poblados ${ }^{9}$.

9 La comarca indicada estuvo sometida a un fuerte influjo celtibérico. Incluso en algún poblado como el denominado de la Peña del Saco de Fitero (territorio de La Rioja), la presencia celtibera, posterior a un incendio, supuso el apogeo del poblado, ver B. TARACENA y L. VÁzQUEZ DE PARGA, “Exploración del poblado celtibérico de Fitero", Príncipe de Viana, 1945; J. MALUQUER, "Notas estratigráficas del poblado celtibérico de Fitero (Navarra)", Principe de Viana, 1965. En El Castillar de Mendavia, la presencia de cerámica torneada estuvo acompañada del abandono del poblado. Los pocos materiales obtenidos del poblado I de Cortes de Navarra se sitúan entre el 550-530 a. C., a finales del Hierro I. En otros poblados la situación no parece tan extremada, aunque el descenso cualitativo de los materiales hace pensar en una recesión, como en el Castillo (Castejón de Navarra) y en Castejón de Arguedas, ver A. Castiella, La Edad del Hierro... o. c. pág. 84 para La Custodia de Viana y pág. 168 para El Castejón de Arguedas, además de B. TARACENA y L. VAZOUEZ de PARGA, “Exploración del Castejón de Arguedas”, P. V. 1943. Una visión general de los comienzos y continuidad de los yacimientos realizada con la ayuda de los materiales obtenidos en las excavaciones, por hallazgos casuales y por recogida de materiales de superficie, puede apreciarse en $A$. CASTIELLA, "Nuevos datos sobre la Protohistoria navarra", Primer Congresos General de Historia de Navarra. 2. Comunicaciones, Anejo 7 de Príncipe de Viana, 1987, p. 229. 
Pero el desconocimiento es todavía mayor si como término de consideración y de valoración se tienen en cuenta no la existencia de objetos e instrumentos, sino la identificación y materiales, sino la identificación de estructuras protourbanas y restos de casas. Sorprende a este respecto que los poblados y posibles poblados existentes en la comarca considerada presenten una localización y una dispersión que no recibe un cómodo enlace y continuidad con los oppida registrados en la etapa de la conquista. En este sentido los testimonios de la Edad del Hierro en la comarca son muchos y muy dispersos (ver nota 5), mientras que son varios los oppida de la comarca de época romana que apenas disponen de algunos yacimientos de la Edad del Hierro en su proximidad ${ }^{10}$.

El complejo y dilatado período de reordenación del territorio, la ausencia de datos pertinentes o la inconsistencia de los mismos oscurecen el conocimiento del proceso preciso seguido en el surgimiento de los oppida en esta comarca. Es cierto que para algunas zonas de Navarra se conoce en términos muy generales como se realizó la ocupación y la reorganización del territorio. Parece seguirse en ellas un modelo de reordenación territorial basado en la jerarquización de los poblados, de los cuales uno, el poblado principal, cumplía para el resto funciones de índole política, religiosa y económica. Así en la comarca de Viana, Navarra (territorio berón), el poblado importante de La Custodia, que se identificará con la posterior Vareia berona, desempeñaba el papel de poblado principal para los asentamientos secundarios de La Castellana, La Atalaya, Valdecarro y El Cueto. De manera similar, en la zona de Mendavia, el poblado de El Castillar, que no cristalizará en un oppidum, cumplía dicho papel para los asentamientos menores de Cogote Hueco, Puente Fustero y EI Altillo. Y el solar de Calahorra, con unos pocos restos celtibéricos encontrados en los cimientos de la muralla romana, está rodeado de asentamientos como el Sorbán-Los Arbolazos, EI Valladar, Torrecilla y Campo Bajo.

No sabemos si en la zona en la que surge el oppidum de Cascantum la situación previa era similar. No hay datos definitivos al respecto y desconocemos si el actual solar de Cascante fue sede de un importante poblado de la Edad del Hierro y cabecera de los poblados de los alrededores, antes de configurarse como el oppidum conocido por las monedas y los textos latinos.

10 Las cerámicas de la Edad del Hierro encontradas en Santacara dan a entender que el oppidum de los carenses se levantaba sobre un poblado de la Edad del Hierro. Sin embargo, el oppidum de los cascatenses, conocido por las monedas y los textos literarios, sólo cuenta, por ahora, en relativa cercania, con la existencia de dos pequeños yacimientos en proximidad. En el caso de que la ciudad de Mouskaria, cuyo preciso arranque temporal es desconocido, estuviese ubicada en la zona de Fontellas - algo que no se puede probar - , tendría en proximidad el importante yacimiento de El Castellar de Fontellas, que se proponga hasta el s. Il a. C. Por otra parte, la nueva Grachurris, cuya identificación con las Heras de San Martín de Alfaro (La Rioja) es innegable, tenian su precedente en la antigua llurcis, de ubicación incierta. Es también evidente que la prerromana Calagurris contó con varios asentamientos cercanos. Por último, los diversos poblados existentes en la Custodia de Viana (Navarra), darían razón de la Vareia de los Berones, según reclama una recuente propuesta. 
No sólo se tropieza con esta dificultad, sino que de hecho se desconoce en sus elementos más precisos como estaba organizado e integrado el territorio correspondiente a esta zona de la orilla derecha del Ebro. Y el hecho es que la zona - además del importante asentamiento del Cerro del Castillo de Castejón, que pudo ser parte integrante, quizás, del territorio de la antigua e inidentificable Ilurcis y luego de Grachurrris - ha suministrado testimonios arqueológicos de la época en el paraje junto a la ermita de San Sebastián de Cintruenigo, se han detectado dos pequeños yacimientos cercanos a Cascante, en Buñuel se ha obtenido algún ejemplar cerámico suelto y se cuenta, sobre todo, con el importante yacimiento de El Castellar de Fontellas y el cada vez más recio e importante asentamiento de la Edad del Hierro en el Cerro de Santa Bárbara de Tudela.

Este último lugar ha proporcionado, por una parte, cerámicas descontextualizadas de la Edad del Hierro, pero también se han podido establecer en el mismo niveles arqueológicos con restos de cerámicas hechas a mano, incisas y excisas, que se remontan a comienzos del S. IX a. C., seguidas de otras posteriores realizadas a torno. Por otra parte, en catas efectuadas que distan entre si unos $115 \mathrm{mts}$ se han encontrado restos de estructuras de viviendas de la Primera Edad del Hierro. Este dato, junto con el apoyo que proporcionan el resto de los materiales encontrados, abogan por la existencia de un poblado en ese cerro ${ }^{11}$. Pero teniendo en cuenta la evidencia histórica posterior también parece indudable que dicho poblado, que tiene continuidad como asentamiento en época romana, pues hay también restos de cerámicas al respecto, no consiguió alcanzar en el contexto de los asentamientos del entorno la importancia suficiente que permitiera su transformación de poblado indígena en civitas romana posterior. Tal oppidum se constituyó en Cascantum - se levantase o no se levantase sobre un asentamiento anterior - , y fue el oppidum de Cascantum el que acabó por transformarse en civitas romana. No hay razones directas ni de solidez para ir en contra de la fuerza que proporciona la reducción y similitud homofónica de Cascantum con Cascante e inclinarse por la propuesta de que la Cascantum indígena pudiera estar en Tudela. Se requerirían datos arqueológicos continuos de más peso y algún indicio literario. Incluso en el caso de que posteriores excavaciones confirmaran la existencia en el Cerro de Santa Bárbara de Tudela de un poblado indigena fuerte, amplio y desarrollado y de que en ese supuesto nos las tuviéramos que ver con la presencia de un oppidum indígena, tampoco constituiría razón suficiente para ubicar en Tudela la Cascantum indígena. Por lo que puede deducirse del estado actual de la excavación, es evidente que el poblado de la Edad del Hierro del Cerro de Santa Bárbara de Tudela no evolucionó a civitas romana. En época romana

1 Para los nuevos datos, ver el articulo de J. J. BIENES CALvo, "Desde la prehistoria hasta el s. IX", en El patrimonio histórico y medioambiental de Tudela: una perspectiva interdisciplinar, ayuntamiento de Tudela y Universidad SEK de Segovia, 2001. Nos parece una hipótesis audaz, levantada sobre bases poco firmes, la propuesta de que la Cascuntum indigena pudiera estar en Tudela y no en Cascante. 
su vida es más bien lánguida y apagada a tenor de los escasos materiales encontrados por ahora. Pero en el caso de que hubiera que actuar con suposiciones -y confieso que se trata de una simple hipótesis - la existencia del poblado del Cerro de Santa Bárbara si hay que ponerlo en relación con algún asentamiento de mayor entidad, resultaría menos estridente si se relacionara con la celtibera llurcis y no con la Cascantum indígena. La llurcis mencionada por las fuentes históricas, de localización desconocida pero en la zona de Alfaro, fue la antecesora de la Grachurris y se amortizó cuando Sempronio Graco fundó en la zona ese ciudad. En el supuesto de que el asentamiento tudelano fuese un poblado importante, su decaimiento en época romana pudiera estar justificado por el reajuste poblacional al que dio lugar la fundación de Grachurris. De hecho la zona de Alfaro y Cascante no distan mucho de Tudela.

$Y$ por lo que se refiere a la ciudad vascona de Mouskaria, que aparece aludida por vez primera en los listados de Ptolomeo (floreció este autor que tenía fijada su residencia en Alejandría entre el 127-148 d. C.) y a la que se le otorga hipotéticamente una ubicación en Fontellas, pudiera ponerse en el relación con el asentamiento de El Castellar de Fontellas. Como puede apreciarse se trata de una propuesta hipotética que no solo tiene el inconveniente de que la localización que se otorga a la ciudad no es segura, sino también la dificultad de que la secuencia cronológica y el casi vacío arqueológico que liga el poblado de la Edad del Hierro de El Castellar de Fontellas y el momento desconocido en el que surgió la civitas de Mouskaria es muy amplio e indocumentado.

4. Es de suponer que la nueva forma de organizar el espacio y de articular el territorio se correspondiese con una estructuración social más comple$\mathrm{ja}$, aunque por falta de la pertinente información se pierda el conocimiento de aquellos factores y aspectos concretos que vayan más allá de lo que se sabe de otros lugares. Pero no hay por qué suponer que la situación social en la comarca tudelana fuese muy distinta de la que se manifiesta en otras zonas. De hecho en páginas anteriores ya se ha prestado atención a los fenómenos sociales relacionados con los desplazamientos de población, con las cuestiones de la reabsorción, asimilación y aculturación, usuales entre poblaciones étnica y culturalmente diferentes que entran en contacto.

4.1. No faltan investigadores que consideran como muy plausible que la intrusión de población nueva y foránea crease quizás una especie de aristocracia dominante sobre la masa de habitantes anteriores. Con ello no sólo se tendría un sociedad distinta y más compleja, sino también una jerarquización social subsiguiente abarcando las relaciones dinámicas entre unos supuestos dominadores y dominados. Me temo que se trata de un esquema muy simple y, por ende, excesivamente radical. Los testimonios arqueológicos no sólo no avalan una visión tan radical, sino que lo exiguo de los mismos y las dimensiones, no muy exageradas, que alcanzan los cambios que 
se producen en esta comarca en el tránsito del Bronce Final a la I Edad del Hierro desaconsejan situar en este período coincidente con la intrusión de población foránea la configuración de una sociedad más compleja y jerarquizada. Teniendo en cuenta los datos arqueológicos, lo sucedido en otras zonas peninsulares mejor conocidas y el propio desarrollo histórico, parece que el proceso destacable de diferenciación económica y social y la consolidación de una élite indígena hay que situarlos a lo largo del período de la Edad del Hierro II $^{12}$.

4.2. En el tipo de organización económica del Bronce Final, en el que las poblaciones apenas tenian superávit, las formas de distribución de bienes y servicios eran muy elementales: la familia o la población del pequeño asentamiento que los producía. Eran unidades básicas productoras-consumidoras y producian muy pocos excedentes que no permitian un uso frecuente de los mecanismos de tráfico y comercio. Por el contrario, los avances e innovaciones culturales debidos directa o indirectamente a la población indoeuropea produjeron un desarrollo económico mayor y este desarrollo llevó inevitablemente a una diferenciación social más grande. Es cierto que los escasos testimonios arqueológicos disponibles apenas permiten hacerse una idea, muy general ciertamente, del desarrollo económico alcanzado en las tierras de la comarca de Tudela. Ésta era capaz de conseguir un desarrollo económico muy grande, pues disponía de tierras llanas de gran extensión , muy fértiles y muy apropiadas al cultivo cerealista. Con esas posibilidades productivas podía atenderse suficientemente la población y su subsiguiente crecimiento demográfico, que a juzgar por los materiales arqueológicos disponibles era muy superior al experimentado durante el Bronce Final.

Con los poblados de la Edad del Hierro, el anterior sistema económico y la sencilla estructura de distribución de bienes y servicios imperante sufrieron un proceso de transformación cuantitativa y cualitativa. En este sentido, no se dispone en la comarca con datos especificos que lleven a pensar que la propiedad comunal imperase en la economia de los poblados y que su sociedad estuviese poco diferenciada. Algunos de los pocos datos disponibles van en otra dirección. La necrópolis del Castillo de Castejón ha proporcionado un conjunto de datos muy sugerentes, que si se consolidan en la línea que hasta ahora apuntan, evidenciarían reveladoras transformaciones en la sociedad

12 No se puede afirmar como si se tratara de algo conseguido, pues se carece de la pertinente información, que la población autóctona ofreciesen o no resistencia a la penetración cultural y militar indoeuropea. Tampoco que los indoeuropeos, cuyo número de asentados es difícil de determinar, constituyesen una casta dominante, ni que el reparto del territorio se hiciese sin problemas bajo la simple y gratuita suposición de que los foráneos prefirieron las zonas ricas y llanas y los nativos las zonas agrestes. Desatinadamente seria tarito como afirmar que toda la población por debajo de la línea imaginaria Lumbier-Pamplona-Leguín, que acogía a la mayoría de la población, era indoeuropea o nativa reabsorbida, en detrimento de los teónimos y antropónimos de raigambre vascona, ibérica, celtibérica registrados en esa amplia zona. Indicar los cambios arqueológicos que se han producido, tal y como se ha hecho en la nota 8 , resulta más adecuado que elucubrar al respecto. Estos datos, valorados en sus dimensiones económicas y sociales, son suficientes para percibir que se estaba consolidando una sociedad más fuerte y evolucionada. 
y en el sistema económico. Así, una de las tumbas exhumadas presenta una construcción más compleja y cuidada que las demás, y un ajuar más rico. Un murete circular rodea la urna de un personaje y contiene los enterramientos de personas que pudieran estar relacionadas con él. El realce constructivo dado a esta tumba, su distinción entre otras con las que parece estar asociada y la riqueza de los ajuares (algunos de cuyos objetos son resultado de un comercio con el mundo mediterráneo, al decir de los excavadores), son elementos que apuntan hacia una manifiesta desigualdad social.

4.3. No se estaría muy alejado de la realidad si se pensara que la reordenación y estructuración del territorio comarcal, se hiciese o no bajo la fórmula de una jerarquización de los poblados, estimuló las actividades agropecuarias, provocando un aumento cuantioso de la producción. En otras regiones peninsulares se conoce muy bien que parte de esos excedentes agropecuarios se concentraron en manos de un grupo reducido de personas, que controlaban los medios de producción y actuaban además como agentes de distribución. Cabe sospechar que así sucediese también en la comarca considerada y que minorías dirigentes indígenas en su papel de controladores de los medios de producción y en su función de distribuidores de los bienes de consumo, comenzasen a sobresalir y a destacarse del resto de la población foránea o autóctona, que todavía estaría, quizás, integrada y enlazada a través de instituciones de carácter gentilicio. Los miembros de estas elites indigenas han podido ser los consumidores de aquellos objetos encontrados en la zona, pero extraños a ella, que pudieron llegar allí por vía comercial.

Desconocemos si las formas de organización de carácter gentilicio comenzaron a difuminarse en la comarca, como consecuencia del surgimiento y consolidación de estas élites indígenas. No obstante, por lo que ello pueda significar, conviene recordar al respecto que el territorio navarro, a diferencia de lo que sucede en otras zonas de dominio celtibérico, no se registran testimonios alusivos a unidades indígenas de integración social ${ }^{13}$. De manera similar se carece de información acerca de las formas adoptadas por las comunidades indígenas en la posesión y explotación de las tierras que contro-

13 Con excepción de las téseras de hospitalidad de Viana (Navarra), cuyo territorio es muy probable que perteneciese a los Berones, la inscripción recogida en B. TARACENA y L. VÁzQUEZ DE PARGA, Excavaciones en Navarra, V: La romanización en “Príncipe de Viana 7; Pamplona, 1946, 45. ${ }^{\mathrm{a}}: \mathrm{XXX} / \mathrm{D}(\mathrm{eo}) \mathrm{m}(\mathrm{agno})$ $\mathrm{P}$ (eremusta)/ $(\mathrm{F})$ esine/ Tala(i)/orum constituiría el único epigrafe procedente del solar navarro que menciona una posible unidad social de carácter suprafamiliar, si bien esta misma inscripción ha sido objeto de una interpretación que elimina su carácter gentilicio, ver al respecto H. GIMENO y J. VALEZA, "Correcciones de lectura a algunas inscripciones romanas de Navarra", Sylioge epigraphica barcinonensis, 17:5, 1994, pp. 190-200. Para la cuatro téselas de hospitalidad de Viana (Navarra), ver J. LABEAGA, J. UNTERMANN, "Las téselas del poblado prerromano de La Custodia, Viana (Navarra). Descripción epigrafia y lingüistica", Trabajos de Arqueología Navarra 11, 1993-94, pp. 45-53. Los textos de estas téselas proporcionan indicios suficientes para suponer que la lengua de la zona de Viana era la celtíbera. Dentro, por supuesto, del ámbito de propuestas hipotéticas alguno de los elementos lingüísticos de estas inscripciones pudiera contener un etnónimo o el nombre de una gentilidad. Otros, sin embargo, pudieran corresponder a una indicación de origen o procedencia o a una expresión de filiación. 
laban. Se desconoce, en definitiva, para estos momentos si la tierra, la fuente básica de producción, era poseída colectivamente por el grupo y distribuida para su uso entre sus miembros o, por el contrario, era mayoritariamente de propiedad privada. De lo que no hay duda es que desde los primeros momentos de la conquista las fuentes escritas aluden a oppida y pueblos fuertemente consolidados en su dimensión económica, política y social.

5. Durante la Edad del Hierro II, la comarca tudelana, al igual que otras zonas de Valle Medio del Ebro, recibió presiones militares y fuertes influjos culturales de los celtíberos. Los poblados de la Peña del Saco y de Castejón de Arguedas son testigos de ello. Un claro horizonte cultural celtibérico se aprecia en una de las fases de Partelapeña (El Redal, La Rioja) y el predominio de cerámica celtibérica se hace patente en la cima del cerro de La Custodia de Viana (Navarra). Y esta presencia y este arraigo étnico-cultural celtibérico queda expuesto posteriormente de manifiesto por los rótulos de las monedas acuñadas por algunas de las ciudades indígenas de la zona.

5.1. Sobre estos cambios que se estaban produciendo sobrevino la presencia romana que aceleró el proceso de los cambios políticos, sociales y económicos iniciados ${ }^{14}$. Para los romanos la zona tenía un enorme valor estratégico, pues era tierra de frontera y camino de penetración hacia zonas no dominadas. Remontando el Ebro por su orilla izquierda se accedía con rapidez a las tierras del Prepirineo y por su orilla derecha se tropezaba con fáciles caminos que daban entrada a la Meseta Superior. No es extraño, por tanto, que desde fechas tempranas, los romanos, con objeto de establecer su control, concentraran sus esfuerzos sobre la comarca que se extiende desde Caraues o Caravis (Magallón) hasta Calagurris (Calahorra). De esta forma, los antiguos propietarios del territorio dejaron de ser dueños de unas

14 Es preciso prescindir de la mención a los Vascones realizada por Rufo Festo Avieno, autor cuya vida literaria se desarrolló entre los años 310 y 386 d. C., en su Ora Marítima (vv. 250- 251: dictos Hiberos non ab illo flumine/ quos inquietos vasconas praelabitur), pues se trata de una probada interpolación. La segunda referencia literaria a los Vascones corresponde al poema Punica de Silio itálico, que incide en el modo de pelear de los Vascones, sin cascos y armados a la ligera. Los pasajes en cuestión, siguiendo la edición de $L$. BAUER, 1890-1892, 2 vols, son: III, 357-8; V, 195-197; IX, 227-232; X, 13-16). Este poeta vivió entre el año 25 y el $101 \mathrm{~d}$. C., mientras que los hechos narrados corresponde a la Segunda Guerra Púnica (218-202 a.C.). Cabe pensar que Silio Itálico no inventa, ni manipula ni recrea estas noticias, sino que las toma de uno o de varios autores. A. Schulten y Mañaricua suponen que la fuente utilizada es Posidonio. Sin embargo, la fuente en cuestión sigue siendo una incógnita. Es sintomático en este sentido que Estrabón, que utiliza con profusión a Posidonio y recoge muchos datos etnográficos de los pueblos de la Peninsula, no diga nada al respecto y predique otras cosas de los Vascones. Estrabón, por ejemplo, señala que los lusitanos combatian a la ligera, rasgo que Silio Itálico predica de los Vascones.

Un posible y primerizo reclutamiento vascón por parte de Anibal no se contempla en ninguna otra fuerte escrita, salvo en Silio Itálico. Por otra parte, hay serios reparos históricos que oponer a la posibilidad de que dicho reclutamiento se hubiese efectuado realmente. No se tiene conocimiento de que las correrías cartaginesas por la Aníbal reclutó ese ejército lo utilizó en la lucha contra ausetanos, ilergetes, bargusios y lacetanos, antes de atravesar los Pirineos y lanzarse contra Italia. Por otra parte, la mencion de combatientes vascones en el ejército de Anibal es una noticia que no puede contrastarse con otros documentos. De esta forma, el valor y credibilidad de la noticia aportada por Silio Itálico no depende exclusivamente de él, sino que deriva, primordialmente, de la validez y de la credibilidad de la fuente o fuentes utilizadas, que, como ya hemos dicho, son desconocidas para nosotros. 
tierras que pasaron a ser romanas con inusitada celeridad hasta tal punto que las fuentes greco-latinas apenas proporcionan en adelante noticias de esos pueblos, mucho menos detalles y peculiaridades étnico-culturales de los mismos. De este modo, las fuentes históricas, abocadas principalmente a registrar los hechos de la conquista, proporcionan pocas noticias sobre pueblos y demarcaciones geográficas que ocupan los pueblos que ofrecen poca resistencia al invasor. Esta escasez de noticias y lo poco revelante de la mismas no permiten determinar emplazamientos precisos para estos pueblos y los cambios dinámicos de situación que experimentaron. Por el contrario se conoce mejor las demarcaciones territoriales y las características étnico-culturales de aquellos pueblos que ofrecieron una dura y feroz resistencia al invasor.

5.2. Así, cuando en el 195 a. C. Catón asumió el gobierno de la Citerior, y una vez que regresó de la Turdetania ${ }^{15}$ luchó y sometió a sedetanos, ausetanos y «lacetanos» (¿iacetanos?) para luego, ayudado por un grupo de jóvenes suessetanos combatir a los «lacetanos» (iacetanos?). Tito Livio cita a estos pueblos de forma conjunta, dando a entender con ello que se encontraban en vecindad. De esta forma, la tarea de ubicar a estos pueblos en su correspondiente sector geográfico se veía facilitada, sobre todo si se conocía con cierta fiabilidad el espacio ocupado por uno de ellos. Por ejemplo, los sedetanos que tenían a Salduie como ciudad más occidental, ocupaban densamente los valles de los ríos Martín y Gaudalote. A su vez, el grupo de los ausetanos mencionados en esa cita se situaria al sur del Ebro, principalmente en tierras de los valles Guadalote y Matarraña, en opinión de varios investigadores. El pueblo suessetano se asentaría sobre todo en tierras de

15 R. KNAPP, "Cato in Spain 195/94 B.C.: Chronology and Geography" en C. Derux (ed.) Studies in Latin Literature and Roman History II, Bruselas, 1980, p. 43 sitúa este episodio al regreso de su campaña de la Turdetania. T. Livio $(24,20)$ es el autor que nos narra estas campañas contra sedetanos ausentanos y lacetanos (¿iacetanos?: ea tam exigua manu oppida aliquot cepit. Defecere ad eum Sedetani, Ausetani Suessetani. Lacetanos, deviam et silvestrem gentem, cum insita feritas continebat in armis, tum conscientia, dum consul exercitusque Turdulo bello esset occupatus, depopulatorum subitis incursionibus sociorum. La propuesta de sustitución de «lacetani» por «iacetani» se ha defendido desde finales del siglo XIX por diversos investigadores como E. HüBNER y K. GÖTZFRIED (E. Hübner, "Drei hispanisch Völkerschaften", Hermes I, 1886, p. 337 y ss; K. GöTzFRIED, Annalen der römischen Provinzen beider Spanien von der ersten Besetzung durch die Römer bis zum letzten grossen Freiheitskampf, (tesis doctoral), Erlangen, 1907), referencias bibliográficas tomadas a P. V. Gimpera ("Los celtas y el Pais vasco", RIEV, 1932, pp. 457-486). Ver también al respecto G. FATAS, "Hispania entre Catón y Graco. Algunas precisiones basadas en las fuentes", Hispania Antiqua 5, 1975, pp. 269 y SS; J. J. SAYAS ABEngOCHEA, "Conquista y colonización del Valle del Ebro en época tardorepublicana y Principado", en E. Ortiz de Urbina y J. Santos (eds.) Revisiones de Historia Antigua II: Teoría y práctica de ordenación municipal en Hispania, Vitoria-Gasteiz, 1996, pp. 64-66. P. Jacob, “Un doublet dans le geographie livienne de l'Espagne antique: les Ausetans de l'Ebre", Kalathos 7-8, 1987-1988, pp. 135147 sugiere a modo de hipótesis que el pueblo de los Ausetani estaba integrado por dos ramas. Una de ellas se encontraría en la zona del Ebro y sería la que formaba vecindad con ilergetes, sedetanos, suessetanos y celtíberos.

Poco tiempo después, en el 188-187 a. C., L. Manlio Acidio derrotó a los celtíberos en la zona de Calahorra. T. Livio, 39, 21,8-10: paucos post dies maiore coacto exercitu Celtiberi ad Calagurrim oppidum ultro lacessiverunt proelio romanos, nihil traditur, quae causa numero aucto infirmiores eos fecerit, superati proelio sunt: ad duodecim milia omnium caesa, plus duo capta, et castris romanus potitur 
las Cinco Villas y territorios bardeneros de Aragón y Navarra ${ }^{16}$. Los «lacetanos" del texto - este es el término que registran todos los manuscritos-, puede sustituirse sin violencia en este pasaje por el etnónimo iacetani ${ }^{17}$, teniendo en cuenta la secuencia histórica de los acontecimientos y la identificación del espacio geográfico atribuido a los pueblos con los que las fuentes indican que tienen vecindad. Ello no suponga ni implique suprimir pura y llanamente la existencia de unos Lacetani cuya mención recogen otras fuentes en referencia a otros acontecimientos.

$Y$ apenas habia transcurrido un lustro cuando el propio Tito Livio especifica que el gobernador Manlio Acidio luchó en el año 188-187 a. C. contra los celtíberos en las proximidades de Calagurris y les causó 10.000 bajas. Pocos años después, en el 184 a. C., Terencio Varrón conquistó la Suessetania. Estas operaciones de conquista tuvieron como consecuencia pérdidas humanas, cambios en las relaciones de fuerza entre indigenas y alteraciones en el panorama del poblamiento y de la ocupación territorial. Todo ello facilitó el camino para que arraigase la actividad política y administrativa desarrollada por Sempronio Graco y que transformará profundamente la comarca. Lo que se deduce como hecho incontestable de las fuentes históricas es que los romanos estaban combatiendo en tierras fronterizas vasconas, aunque no se mencionen como tales, o, al menos, en los aleda-

${ }^{16}$ Los suessetanos no era un pueblo montañés, sino un pueblo de llanura, asaltado frecuentemente por sus vecinos de la montaña, los belicosos jacetanos. El pasaje mencionado de Tito Livio $(24,20)$ referente a acontecimientos del año 195 a. C., da a entender que los suessetanos estaban en vecindad con los jacetanos y sedetanos de raigambre ibérica. Con ello, las posibilidades de situarlos en el espacio se reducen felizmente. Es usual la propuesta de que ocupaban las tierras de las Cinco Villas aragonesas y los territorios bardeneros de Navarra y Aragón. Se conoce que en el 184 a. C. Terencio Varrón sometió a los suessetanos: Tras un trabajoso sitio con máquinas y obras de asedio, tomó su capital, Corbio y vendió los prisioneros: In citeriore A. Terentius in Suessetanis oppidum Corbionem vineis et operibus expugnavit, captivos vendidit. Según A. Tovar, Iberische Landeskunde, tomo. 3. Tarraconensis, Baden-Baden, 1989, p. 41) este acontecimiento ha podido significar la aniquilación, al menos política, de los suessetanos, pues dejan de estar mencionados en los documentos históricos. No obstante, no es esta la última alusión: Plinio (III, 3,24) ofrece la expresión Oscenses regionis Suessetaniae y en una inscripción (CIL, VI, 1446) se alude a unos Sussetanei (sic) y a unos Segobrigenses. Posteriormente las fuentes literarias atribuirán estas tierras a los Vascones.

Se trataba de un pueblo de carácter celta como puede apreciarse en el etnónimo suessetanos relacionable con el de los celtas galo-belgas suessiones. También el nombre de su capital, Corbio, presenta una apariencia lingüística con el topónimo Corbeil, lugar que se encuentra en las proximidades de Soissons. También el etnónimo suessetani tiene una gran semejanza formal con la ciudad caristia Suesatium. Se supone como muy probable ( P. Bosch Gimpera, "Los celtas y el Pais Vasco", RIEV, 1927, pp. 457-486) que el pueblo celta de los suessetanos fuese el responsable de algunos topónimos que llevan el sufijo -dunum, como Gordún, Berdún y Navardún. El primer elemento de este último topónimo se pone en relación con la raiz del nombre de Navarra y navarri, remitiendo hipotéticamente a esta época la verosimil e incomprobable existencia de una oscura comunidad de los navarri. A. Schulten ("Las referencias sobre los antiguos vascones hasta el año 800 después de J.C.", RIEV, 1927, p. 225 y ss) considera, sin contrastarla con otras referencias, que la primera mención a los navarri se recoge en la Vita Karoli Magni de Eginhardo: ipse per bella memorata primo Aquitaniam et Wasconiam totumque Pyrinei montis iugum et usque ad Hiberum amnem qui apud Navarros ortus et fertilisimos Hispaniae agros secans sub Dertosae civitatis moenia Balearico mari miscetur = "como consecuencia de las guerras mencionadas se anexionó Aquitania, Wasconia, toda la cadena de montañas de los Pirineos hasta llegar al río Ebro que nacido junto a los navarros y después de pasar por las llanuras más fértiles de Hispania desemboca bajo los muros de la ciudad de Tortosa".

17 Para las cuestiones relacionadas con la sustitución de lacetani por iacetani, ver G. FATAS, Sobre los sedetanos, Zaragoza, 1968, pp. 175 y ss. 
ños orientales y meridionales de los Vascones, desde una fecha tan temprana como la del año 195/94 a. C.

5.3. La estabilización de las tierras del valle medio del Ebro, que alcanzará de lleno a la comarca de Tudela, fue una consecuencia de las operaciones militares de Tito Sempronio Graco contra los celtíberos. La batalla de Complega y el sometimiento de la ciudad de Ergavica son dos momentos importantes de esta lucha. Pero los celtiberos no dejaron de ser definitivamente dueños de la zona hasta que fueron derrotados junto al Mons Chaunus (Moncayo) y Sempronio Graco les obligó a ajustar una "paz verdadera y no tan inestable como antes" ${ }^{18}$. Con ella acabó la resistencia de los celtíberos de la zona y el ejército romano dispuso de una retaguardia fuertemente consolidada. Las tierras del Moncayo y aledaños, el valle del Jalón y la comarca tudelana y tierras adyacentes dejaron de ser un problema para los romanos que pudieron dirigir su atención hacia la Celtiberia interior. En la zona conquista que servía de retaguardia, Sempronio Graco suscribió pactos con comunidades indigenas y adoptó medidas estratégicas instalando asentamientos urbanos en los lugares que consideró oportuno como sucede con Grachurris. Se desconoce, por ejemplo, cuando fue suscrito el pacto de alianza de los tarracenses con los romanos. Es posible que se realizase durante la conquista del sector geográfico en el que probablemente estaba enclavada esa ciudad o con ocasión de la política de pactos desarrollada por Sempronio Graco. Esta comunidad estaba asentada en la parte oriental del territorio vascón, que pudo ser quizás anteriormente suessetano, y Plinio en la Historia Natural $(I I I, 3,24)$ la califica de ciudad federada.

T. Sempronio Graco rindió y destruyó muchas ciudades, en número variable $-103,200,300$ etc. - , según la fuente utilizada. La valoración de todas ellas como ciudades es cuestionada por varios autores antiguos. Suponen que por afán laudatorio se consideran ciudades lo que simplemente eran pequeñas aldeas o lugares fortificados. Cuando Estrabón desea determinar la entidad de los asentamientos capturados o conquistados utiliza los términos concretos y precisos komai y pyrgoi, frente al vocablo griego polis o los latinos oppidum o urbs que utilizan otros autores para caracterizar ese mismo acto de conquista y sumisión ${ }^{19}$. La mayoría de las plazas conquistadas pertenecían a la provincia la Citerior y les fueron destruidas o cap-

18 T. Livio, 40, 50, 2-3: magnoque eum postea proelio ad montem Chaunum cum celtiberiis a prima luce ad sextam horam diei signis collatis pugnasse. $Y$ en lo que se refiere a la noticia de una paz verdadera y más estable, T. Livio, 40,50 5-6: veramque pacem, non fluxa, ut ante, fide celtiberos fecisse. Sobre Celtiberia en las fuentes antiguas, ver A. Capalvo, Celtiberia. Un estudio de fuentes literarias antiguas, Zaragoza, 1996.

19 Estrabón en el pasaje III, 4,13 de su Geografía dice que Posidonio tenia una opinión contraria a Polibio ( $X X V, 1,1$ ) cuando este último decia que Sempronio Graco destruyó (katalûsai) 300 ciudades (póleis), dando el nombre de ciudad a asentamientos fortificados (púrgoi). Insiste en que los autores embellecen y exageran los hechos de tal manera que los que dicen que Iberia tenian 1000 ciudades (póleis) dan el nombre de ciudad a aldeas (komai). No especifica el ámbito geográfico en el que se capturaron esos castros y asentamientos, pero es innegable que en el contexto de la narración los celtiberos están implicados. 
turadas a los celtíberos. Bastantes de ellas lo fueron con mucha probabilidad a los celtíberos de las márgenes del Ebro y afluyentes, aunque desconozcamos en la mayoría de los casos sus emplazamientos y los ámbitos y entidades políticas generales a las que pudieran pertenecer. Pero el número de asentamientos destruidos y capturados, por más que parezca y en realidad sea muy exagerado y general, de todas formas deja entrever que la densidad de población de esta comarca era muy alta, las pérdidas muy elevadas y los cambios y reajustes poblacionales muy profundos. Unos pocos años antes de las operaciones militares de Sempronio Graco los suessetanos fueron prácticamente aniquilados en las proximidades de Calagurris, perdiendo los celtíberos 12.000 hombres. Por su parte L. Postumio, colega de Graco, aniquiló en la Citerior a 40.000 enemigos, y en la batalla ya mencionada del Mons Chaunus los celtíberos perecieron más de 22.000.

En el contexto de los generales y gobernadores de se época Sempronio Graco fue más renombrado por su gestión política-administrativa que por sus conquistas y prudencia en la represión posterior. Su actividad política buscó la constitución en la provincia de un espacio territorial en el que reinase la calma y no se corriesen riesgos extremos. Evidentemente la consecución de la tranquilidad y estabilidad en el interior de la provincia no se lograba con actos voluntaristas y buenas intenciones. Se acompañó con pactos, con el establecimiento de normas fiscales y administrativas regulares a las que los nativos debian atenerse y con el desarrollo en los amplios confines fronterizos de una cuidada "política de fronteras" prohibiendo, por ejemplo, que los indígenas levantasen nuevas ciudades por propia iniciativa, tal y como pone de manifiesto Apiano (lb., 43-44). Sabía por experiencia que los centros amurallados indígenas se convirtieron en ocasiones en duros obstáculos que entorpecieron la conducción de la guerra. No podía conceder gratuitamente a unos indígenas apenas pacificados plena libertad en la construcción de nuevas ciudades. Era consciente de que en cualquier momento los nativos, que ya se habían revelado en el pasado como poco escrupulosos en el cumplimiento de los pactos, sintieran la irresistible

Floro $(1,33,9-10)$, que no se plantea la veracidad de la noticia ni su probabilidad, utiliza el término urbs como indicativo de los asentamientos capturados, diciendo que Graco destruyó (eversione multavit) a los celtíberos quinquaginta urbium. Tampoco en este caso se concreta el marco geogrático.

Orosio (IV, 32) utiliza, por el contrario, el término más ambiguo de oppidum, con un campo semáritico que alcanza el concepto de ciudad, pero también el de pequeño lugar fortificado. Desde el punto de vista geográfico diferencia entre la 105 fortalezas (oppida), vacias y abatidas por la guerra que Sempronio Graco obtuvo por rendición (deditionem coegit) en la provincia Ulterior, y las 200 fortalezas (oppida) asaltadas y capturadas (expugnavit et cepit) también por él en la Citerior.

Por su parte Tito Livio, en un pasaje $(40.49,1)$ que refiere acontecimientos anteriores a la batalla de Mons Chaunus, señala la intención de Graco de dirigir sus legiones ad depopulandam Celtiberiam e indica, además, que por miedo o por propia voluntad se entregaron (in deditionem accepit) 300 ciudades (oppida).

Tito Livio y Orosio, a diferencia del resto de informantes, añaden el dato complementario de la forma bajo la que se produjeron esas rendiciones, con aparentes implicaciones legales. La fórmula es similar: deditionem coegit en Orosio, in diditionem accepit en Tito Livio. Para la diferencias que median entre una rendición con una deditio in fidem y una rendición in deditionem, ver W. Dahlheim, Struktur und Entwicklung 
tentación de convertir las ciudades fortificadas en focos de resistencia, desbaratando con ello la fructífera política provincial establecida por Sempronio Graco. Era, por tanto, preferible que los romanos tomaran la iniciativa y fuesen ellos mismos los que procediesen a la creación de centros urbanos en los lugares adecuados a sus intereses, generalmente en el llano, y con los componentes humanos que considerasen oportuno. Eso es lo que hizo Sempronio Graco con la creación de la ciudad de Grachurris ${ }^{20}$. Por otra parte, la abundante concentración de nombres Sempronios en las zonas del Alto y Medio valle del Ebro y tierras adyacentes ${ }^{21}$, si bien se datan en distintos momentos históricos, hacen conjeturar que la política integradora protagonizada por Graco no fue improductiva y que sus efectos perduraron en el tiempo.

6. En la comarca tudelana, en territorio considerado posteriormente como vascón, se fundó la ciudad de Grachurris (en las Eras de San Martín de Alfaro, La Rioja). En Alfaro, solar como decimos de la antigua Grachurris, se ha encontrado un grafito cerámico que ofrece la leyenda incompleta l.u.e.i.ka.r. Esta leyenda da que pensar en la entidad y situación lingüística de la comarca. Se piensa que la secuencia lingüistica -kar del grafito cerámico pudiera ser el sufijo -kar, usual en muchos nombres ibéricos. Es una hipótesis con la que se apunta a que la comarca pudiera ser usuaria de la lengua ibérica. Pero de manera similar pudiera utilizarse otra hipótesis que considera que dicha secuencia encajaría también en el celtibero, si lo que seguía a -kar era una o, dando -karo, genitivo singular de un nombre temático que tuviera como elemento de composición -karo, "querido, amado", tal y como opina J. GORROCHATEGUI'2?.

Por otra parte el topónimo Grachurris se considera un híbrido latino-indigena formado con base en el nombre de Graco y el elemento indígena -gurris, *Graco-gurris, que daría Grac(h)urris. Ofrece en su composición un segundo elemento que ya se daba en el nombre de la cercana ciudad de Calagurris. El elemento nativo -gurrris parece ajeno al celtíbero, pero sin embargo no puede perderse de vista el hecho innegable de que la ciudad de Calagurris, que también porta ese elemento en su composición, acuñó mo-

20 A. HERnÁndez Vera y P. CASAdo López, "Graccurris: la primera fundación romana en el valle del Ebro" en Symposion de Ciudades Augusteas II, Zaragoza, 1976, pp. 23-29 identifica la ciudad de Gracchurris con el lugar denominado Eras de San Martin, en la afueras de Alfaro. Se encontraron restos arqueológicos que van desde el Bronce Final hasta el Bajo Imperio, destacándose su fase celtibérica, ver $\mathrm{J}$. A. HeRnANDEZ Vera, "Difusión de elementos de la Cultura de Cogotas hacia el Valle del Ebro", I Coloquio sobre Historia de la Rioja, en Cuadernos de Investigación de Historia 9, 1983, pp. 70-71.

${ }_{21}$ Para la distribución en la Península de los nombres de la viejas familias romanas, ver S. L. Dyson," The Distribution of Roman Rupublican Family Names in the Iberian Península", Ancient Society 11-12, 1980-1981, pp. 263-266.

22 El grafito cerámico con la leyenda l.u.e.i.ka.r (faltando el resto a partir de la $r$ ) es dado a conocer por J. A. Hernandez Vera y J. NúNEz MARCÉn, "Un nuevo antropónimo indigena sobre cerámica, procedente de Graccurris", Veleia 6, 1989, pp. 207-214. J. Gorrochategul, “Los Pirineos entre Galia e Hispania: las lenguas", Veleia 12,1995, p. 190 realiza los comentarios lingüisticos aludidos. 
neda con rótulos en lengua celtibérica. $Y$ es evidente que ninguna comunidad emite monedas con leyendas en una lengua inusual y que no fuese la que hablaban sus habitantes, a no ser que se hubiese producido un fenómeno de expansión o de sustitución lingüística. No sería nada extraño, pues es evidente que tres lenguas, el ibérico, el celtíbero y la lengua de los vascones confluyen dinámicamente en territorio navarro. $Y$ en este sentido los cambios producidos en los momentos inmediatamente anteriores a la conquista, por un lado, las masacres causadas por ésta, las destrucciones, las alteraciones en las fronteras interétnicas y los cambios en la ocupación territorial que acompañaron a la conquista e implantación del dominio romano constituyen en principio las circunstancias menos apropiadas para que se mantuviese inalterable la situación lingüística de la comarca. La guerra y la conquista fue un factor de alteración que pudo favorecer a una lengua en detrimento de otra, con arreglo a las circunstancias cambiantes e intereses romanos. En este sentido, aunque bien es verdad que se trata de un lugar situado en la franja de la Navarra Media, documentos lingüisticos procedentes de la ciudad de Andelos apuntan a una situación lingüística enrevesada y compleja, y sin embargo no se le conocen sucesos de guerra amplios e intensos que avalen hipotéticamente ese panorama ${ }^{23}$.

6.1. La conquista del Valle Medio del Ebro acabó prácticamente en el 178 a. C. y se vio facilitada por la paz con arévacos, titos, belos y lusones. Por la orilla izquierda del Ebro la conquista se detiene en los aledaños del territorio vascón, al menos las fuentes no registran confrontaciones con vascones en esta época. $Y$ por la orilla derecha, el espacio conquistado y pacificado no llega más allá de Vareia y por el sur se extiende por territorio lusones para detenerse en territorio arévaco.

La fundación de Grachurris viene a ser algo asi como la culminación de la etapa de conquista de la zona. Se considera sin razones de peso que no es una fundación romana propiamente, esto es una fundación con gentes romanas o nativos muy romanizados, sino un primer ensayo en la zona con la pretensión de hacer coexistir juntas dos comunidades ${ }^{24}$. En el resumen del libro 41 de Tito Livio aparece el término constituit, cuyas implicaciones

${ }^{23}$ La ciudad y el territorio de la ciudad romana de Andelos han proporcionado datos lingüisticos muy dispares entre si. Evocan la compleja situación lingüística, simultánea o sucesiva, que pudieron vivir los habitantes de algunas ciudades vasconas. Asi, en momentos previos a la presencia romana, el poblado indigena de la posterior ciudad de Andelos presenta los tipicos materiales de las gentes indoeuropeas. Sin embargo, como sugiere J. Gorrochategui ("Los Pirineos...o. c. p. 221), el topónimo Andelos, al igual que el de Pompaelo, ofrece un segundo elemento -elo, antecedente del vasco iri, irun, "ciudad". Tras la configuración de Andelos como ciudad romana, y en unos momentos que se sitúan en el siglo I a. C., se atestigua una casa pavimentada con una inscripción en grafía y lengua ibéricas ( $M^{a}$ A. Mezquiriz,"Inscripción ibérica en Andelos (Mendigorria, Navarra)", Estudios sobre Arqueologia Ibérica y Romana. Homenaje a E. Pla y Baliester, 1992, Valencia, $347-$ 348), aunque algunos de los nombres contenidos en ella tienen paralelos en la nómina de nombres celtibéricos. Por otro lado, el teónimo Larrahi de ascendencia vascona procede del territorio de esa ciudad, y de la ciudad proviene el antropónimo Urchatetelli (genitivo), construido sobre una base que tiene claros paralelos ibéricos, pero con la peculiaridad fonética de la geminación que le acerca a fenómenos fonéticos aquitanos.

${ }^{24}$ En sus interesantes trabajos N. Dupré ("La place de la vallée de l'Ébre dans l'Espagne romaine", Mélanges de la casa de Velásquez 9,1973, p. 148 considera que la fundación de Grachurris marca el final 
semánticas implican usualmente fundación, reconstrucción y reestructuración $^{25}$. El hecho de que Sempronio a la manera helenística prestara su nombre a esa ciudad, el hecho de que recibiese en sumisión a los celtiberos como indica este pasaje y el que constituyese esa ciudad para que fuese recuerdo de sus hazañas, hace suponer que la configuración de la nueva comunidad pudo hacerse con una cantidad importante de población y disponer de un amplio distrito rural. En el lugar en el que se ubicaba esta ciudad algunos investigadores aprecian con cierto apresuramiento posibles vestigios de centuriación ${ }^{26}$.

6.2. La derrota y rendición de los celtíberos dejaba al gobernador amplio margen para la configuración de una nueva comunidad. Y esta idea de reconstrucción y configuración de una nueva comunidad se obtiene también de una referencia de Festo en la que se dice que Grachurris, que tomaba su nombre de Graco, se llamaba anteriormente llurcis ${ }^{27}$. Los textos que indican la creación de esta ciudad y que en cierta manera sugieren la configuración de una nueva comunidad no hacen suponer que se crease con una doble población romano-indígena: colonos veteranos e indígenas, como suponen A. García y Bellido y J. $M^{a}$ Blázquez. De esa doble comunidad romano-indígena no hay dato alguno ${ }^{28}$.

de la conquista de esta zona, insistiendo en el carácter militar del asentamiento, ensayo de convivencia de dos comunidades. Ver también de la misma autora "Frontières et limites antiques dans la vallée de l'Ébre (Espagne)", Caesarodunum 16, 1981, not. 15.

${ }^{25}$ En época imperial, posiblemente entre los siglos III-IV d. C., se realizaron con fines didácticos unos resúmenes (Periochae) muy condensados de los libros de Tito Livio. En Per. 41 se lee: Tib. Sempronius Gracchus procos. Celtiberos victos in deditionem accepit monimentumque operum suorum Gracchurrim oppidum in Hispania constituit.

26 Los propios términos utilizados en el enunciado aclaran suficientemente que se trata de posibles vestigios, ver J. Gómez Pantoja, "Sobre un posible catastro romano en el límite navarro-riojano", Príncipe de Viana 148-149, 1977, pp. 423-433; "Vestigios de una posible centuriatio romana en las cercanias de Alfaro (Logroño)», CNA 15, Zaragoza, 1979, pp. 929-936.

${ }_{27}$ Sexto Pompeyo Festo, autor que vivió avanzada ya la segunda mitad del s. Il d. C., escribió, en veinte libros, un epitome, una especie de diccionario enciclopédico, con explicaciones etimológicas y gramaticales, descripciones de acontecimientos, leyendas e instituciones políticas y sociales. Constituyó un enorme esfuerzo por reunir brevemente toda la información que se disponia en su época. Las entradas estaban ordenadas alfabéticamente. Festo, De verborum sign. Cum Pauli Epit., 97 señala en referencia a esa ciudad: Graccurris, ubs Iberiae regionis, dicta a Graccho Sempronio, quae antea llurcis nominabatur.

${ }^{28}$ A. Garcia y Bellido, en su trabajo sobre las fundaciones coloniales romanas ("Las colonias romanas de Hispania", An. Hist. Der. Esp. 24, 1959, pp. 448-9) asimila el caso de Grachurris al de Itálica o al de Ampurias y considera que comenzó su andadura con una doble población, la indigena y peregrina, que se corresponderia con la antigua llurcis, y la de los colonos romanos. J. $M^{a}$ Blázquez ("Los vascos y sus vecinos en las fuentes literarias griegas y romanas de la Antigüedad", Problemas de la Prehistoria y de la Etnologia Vascas, Pamplona, 1966, pp. 192 y ss) sigue en este aspecto al anterior, y, aunque hace la correcta indicación de que Grachurris nunca recibió el título de colonia, arriesga en exceso al afirmar sin datos que fue una fundación ex novo con una deductio militar o civil, o ambas cosas a la vez. Una doble pobiación romano-indigena.

No haya evidencia ni datos que pudieran avalar propuestas de este género. R. C. Knapp, Aspects of the Roman Experiencie in Iberia, 206-100 B.C, Vitoria-Valladolid, 1977, p. 109 considera poco probable, con buena lógica, la doble comunidad; P.A. Brunt, Italian Manpower, Oxford, 1971, pp. 215 s) considera que la fundación fue destinada a nativos. 
Lo que es innegable es que la ciudad en esos momentos históricos tenía un gran valor estratégico como garante de la paz y tranquilidad de la zona. Como puesto de avanzada protegía la comarca pacificada de posibles incursiones de hordas indígenas, pues se encontraba a no muy larga distancia del territorio de los arévacos independientes. Desde Grachurris se accedía rápida y fácilmente a la Meseta y al territorio arévaco, remontando la vía que formaba el río Alhama. Su posición respondía a la conveniencia de proteger el flaco que miraba a los celtíberos y no el que daba al territorio de los vascones norteños. Para estos últimos, en el supuesto de que no contasen con tierras en la margen derecha del Ebro, este río constituía un obstáculo serio en su tránsito y una línea protectora de primer orden ${ }^{29}$. $Y$ por lo que hace al carácter de su población, que en cierta manera está relacionado con el cometido del lugar, se supone que fue una fundación destinada a acoger nativos, bien antiguos pobladores de llurcis y celtiberos ${ }^{30}$, bien con Vascones proclives a Roma, hipótesis bastante razonable si se tiene en cuenta que la ciudad será calificada luego de vascona ${ }^{31}$.

7. Para la $1 .^{\mathrm{a}}$ y $2 .^{\mathrm{a}}$ mitad del s. II a. C. las fuentes literarias registran en la amplia zona considerada y tierras adyacentes, las fuentes literarias registran para la primera y segunda mitad del s. II a. C. etnónimos como Sedetanos, Suessetanos, Jacetanos, celtíberos de distintos grupos etc., y aluden también a ciudades general y a ciudades concretas como laka, Corbio, llurcis, Gracchurris, Calagurris. Por el contrario no hay referencias en las fuentes a los Vascones y a ciudades vasconas para esas fechas y momentos anteriores, ya que la contenida en la Ora Marítima de Avieno y la recogida en la Púnica de Silio Itálico se trata de una interpolación posterior la primera e incomprobable el grado de objetividad y de fiabilidad la segunda, como se ha argumentado en la nota 13. Los cambios que acompañaron a la conquista fueron importantes, la reordenación del territorio inmensa, pero la metamorfosis que experimentó la zona en su dimensión política y social fue todavía mayor. Era algo esperable, pues los marcos de convivencia cívica y de trato cotidiano y mutuo que proporcionaba la ciudad fueron creando nue-

29 R. C. Knapp, Aspects of the Roman Experiencie o. c. p. 109 considera que la intención que inspiró la fundación de esta ciudad era primordialmente disponer de un asentamiento leal contra los Vascones. $Y$ en la página 148 afirma que Calagurris y Grachurris protegian el alto Ebro contra los Vascones.

30 G. De Pamplona, "Los límites de la Vasconia hispano-romana”, en Problemas de la Prehistoria y de la Etnología Vascas, Pamplona, 1966, p. 208, siguiendo a A. Garcia y Bellido, toma como término de referencia el pasaje ya aludido de la Periocha de Tito Livio. De ella deduce hipotéticamente que Graco instaló celtíberos en Grachurris. Posteriormente G. Fatás, “Hispania entre Catón y Graco», Hispania Antiqua 5 , 1975 , p. 305.

31 En lo que respecta al elemento humano que interviene en la fundación de Grachurris, R. LOPEZ MELERO, “¿Gracchurris fundación celtibérica?», Veleia 4, 1987, pp.171-177 aclara que las fuentes históricas no señalan que Grachurris fuese una ciudad fundada para los celtiberos, sino que se creó después de la derrota los celtíberos y como recuerdo de la victoria sobre ellos. Eso le hace suponer que la fundación se hizo con gentes vasconas, con las que los romanos no han sostenido ningún acto de beligerancia. Al menos las fuentes históricas no los señalan, mientras que si s indicarán posteriormente que la ciudad era vascona. 
vos lazos de unión entre los ciudadanos. Y estos lazos, al decir de Cicerón ${ }^{32}$ prevalecieron sobre la pertenencia a una gens, natio o el uso de una lengua.

7.1. Que las fuentes literarias silencien las alusiones a los Vascones y a las ciudades vasconas no es óbice para que a mediados o finales del siglo II a. C. aparezcan una serie de cecas que dan a entender que en la comarca considerada, en sus aledaños y en territorio calificado posteriormente como vascón había un conjunto de comunidades cívicas que acuñaron monedas con rótulos en grafia ibérica y patrones ibéricos. De hecho, la incorporación de la zona a la actividad monetal coincide con los momentos en los que se produce la introducción y generalización del sistema de escritura. En los trabajos sobre ciudades que emiten monedas no es infrecuente encontrarse con la suposición de que las comunidades emisoras deben estar provistas de un cierto grado de desarrollo urbanístico y disfrutar de formas de vida urbana. Por otra parte la aparición de acuñaciones monetales en esta zona se pone en relación con la presencia del ejército romano, con la exigencia de disponer de numerario para atender las necesidades de la guerra, la recogida de impuestos y el pago a soldados y mercenarios.

7.2. Pero la cuestión es más compleja. Hay un grupo de cecas que los investigadores ponen en relación con el territorio vascón ${ }^{33}$, pero cuyos lugares de acuñación, ciertamente, no han sido identificados. De ellas destacaria la ceca de Barscunes y de Olcairun, cecas que se consideran próximas a Pamplona; la primera con una relación no muy clara con el etnónimo Vascones $^{34}$. Desde el punto de vista cronológico los investigadores sitúan estas cecas en la banda cronológica aproximada que va desde finales de la Gue-

32. Cic De off. I, 17: «Hay, en efecto, en la sociedad humana diversos grados. Partiendo de la más general, hallamos otra, que formada por los que constituyen un mismo pueblo (gens), una misma nación (natio) y hablan idéntico idioma, relaciona entre si a los hombres con sólidos vínculos; pero más estrechos son aún los que unen a los habitantes de una misma ciudad". Es sintomático a este respecto que las ciudades que acuñan monedas lo hacen recogiendo el nombre de la comunidad concreta a la que pertenecian. Fundamentalmente, se acuñaba moneda por razones económicas, pero tampoco era ajeno el deseo de utilizar la moneda como medio de dar a conocer a los demás la comunidad emisora, ver J. J. SAYAS ABENGOCHEA, "Cuestiones relacionadas ....o. C. pp. 107-108

33 A. Beltran, "Notas sobre las acuñaciones ibéricas en Navarra», en Primer Congreso General de Historia de Navarra. 2. Comunicaciones, Anejo 7, Pamplona, 1987, pp. 339-348 realiza una serie de consideraciones sobre estas monedas, incidiendo en la ceca de Olcairun. De ella hace una nueva interpretación a partir de los dos ejemplares de que se dispone. A. Tovar, "Notas lingüisticas sobre monedas ibéricas", Actas del II Coloquio sobre lenguas y culturas prerromanas de la Península lbérica, Salamanca, 1979, pág. 473, interpretaba Olcairun como una forma híbrida compuesta del radical celta Olca (campo sembrado), atestiguado en el topónimo cántabro Octaviolca, y de la altamente insegura forma vasca irun. Pero una vez que $L$. Michelena aclaró que el rotacismo en vasco, esto es, el paso de I a r, de ilun a irun, es un fenómeno de época medieval, la explicación etimológica de ese híbrido pierde su atractivo. Por su parte J. Untermann, "Las leyendas monetales", Actas del I Coloquio sobre lenguas y culturas prerromanas de la Península Ibérica, Salamanca, 1976, pág. 124, ensaya para esta leyenda monetal una explicación a partir de paralelos ibéricos como Olca-iltu-n. Para estas monedas, ver A. Dominguez, Las cecas ibéricas del valle del Ebro, Zaragoza, 1979.

${ }^{44}$ En la ceca de Ba(r)scunes-Bengoda, el rótulo de Bengoda de los anversos se supone que corresponderia al nombre de la ciudad del grupo étnico de los Vascones. Por lo general los rótulos de la monedas se identifican usualmente con el nombre de la ciudad $o$, en su caso, de una comunidad construida sobre la base lingüística del etnónimo. A veces los anversos registran siglas que pudieran tomarse como abrevia- 
rra de Numancia 133 a. C. a los comienzos de la guerra sertoriana. Pues bien en tierras que pudiéramos valorar hipotéticamente como vasconas primigenias la Arqueologia no ha podido detectar para ese período estructuras urbanas ni formas de vida propias de ciudades evolucionadas. Por otra parte, como venimos reiterando continuamente, no hay referencias literarias alusivas a los Vascones y a ciudades vasconas para ese período cronológi$\mathrm{co}$, ni tampoco ningún tipo de información que indique que la parte central del territorio vascón hubiese sido conquistado o se hubiese entregado voluntariamente durante ese período. Y esa falta de información de las fuentes históricas a los Vascones y a la conquista del territorio durante ese período hace pensar y sospechar que el territorio de la zona de Pamplona en la que los investigadores sitúan hipotética y aproximadamente esas cecas no estaba dominado por Roma, lo que sería un gran obstáculo para situar esas cecas en esa zona ${ }^{35}$. Las cecas pudieron estar situadas - y es una hipótesisen algún lugar más próximo al Ebro, en su margen izquierda. En este supuesto el contexto cronológico e histórico resulta menos discordante. En cualquier caso, la aparición de cecas en territorio vascón debió de depender de razones intrínsecas a su propia realidad.

7.3. Por el contrario en los territorios periféricos vascónicos y en las zonas adyacentes la existencia de ciudades, las formas de convivencia urbana, la presencia de ejércitos romanos y el desarrollo de actividades económicas son factores constatables, que pudieron propiciar la aparición en esas tierras de una serie de cecas. Algunas de estas cecas que acuñaron moneda en la segunda mitad del siglo II a. C., con notable intensificación durante la guerra sertoriana, se localizan en territorios ocupados por una misma etnia. Así, a la jerarquización de asentamientos que tenian los indígenas, se sumó, por conveniencia romana, la planificación territorial de las cecas existentes. Hubo ciudades, cabeceras de comarca, que acuñan monedas de plata y bronce, otras que sólo emiten bronce y otras que no

ciones de los nombres recogidos en los reversos, que son indicadores étnicos o ciudades pertenecientes a ese grupo. En la interpretación que algún investigador hace de la leyenda $\mathrm{Ba}(\mathrm{r})$ scunes-Bengoda el primer término daria razón de la etnia y el segundo de una ciudad concreta correspondiente a esa etria. En este sentido, A. Tovar (Estudios sobre las primitivas lenguas hispánicas, Buenos Aires, 1949, p. 83 y "Notas lingüisticas sobre monedas ibéricas", Actas del II Coloquio sobre lenguas y culturas prerromanas de !a Península lbérica, Salamanca, 472-3) veia en este último rótulo la expresión gráfica del etnónimo Vascones, considerándolo como un nominativo de plural de un tema en nasal de una lengua indoeuropea. Por el contrario, J. Untermann (“Zur Gruppierung der hispanischen "Reitermünzen» mit Legenden in iberischer Schrift", Madrider Mitteilungen, 5, 1964, 112 y ss y "Las leyendas monetales", Actas del I Coloquio sobre lenguas y culturas prerromanas de la Península Ibérica, Salamanca, 1976, p 219) considera que se trata de un término formado sobre una base "brask, complementada con sufijo en nasal - on - . Con ello hacía inviable la ecuación establecida por A. Tovar entre el rótulo monetal y el etnónimo Vascones. Para él, la leyenda monetal, que se aproxima al mundo celtibérico, designaria el nombre de una comunidad concreta y no el étnico Vascones.

35 Ver a este respecto J. J. SAYAS ABEngochea, "Cuestiones relacionadas con la etnia histórica de los vascones", en Los pueblos prerromanos del norte de Hispania. Una transición cultural como debate histórico, Pamplona, 1998, p. 100 y nota 42. 
acuñaron moneda. Dejando a un lado la ceca de $\mathrm{Ba}(\mathrm{r})$ scunes de ubicación dudosa, en la comarca tudelana por ejemplo, en tierras calificadas posteriormente de vasconas, Kalakorikos amonedó plata y bronce, Kaiskata sólo bronce y Grachurris no emitió moneda ${ }^{36}$. Por otra parte, en otros sectores territoriales valorados por las fuentes literarias como vascónico y en otros próximos que no lo fueron, también se constatan comunidades cívicas que dispusieron de cecas que emitieron moneda en esta época ${ }^{37}$.

36 Para la descripción y estudio de las monedas de Kalakorikos y Kaiskata, ver L. Villaronga, Corpus nummum Hispaniae ante Augusti aetatem, Madrid, 1994. Para su interpretación y valoración desde el punto de vista lingüistico, ver J. Untermann, "Zu keltiberischen Münzelegenden", Archivo Español de Arqueologia, 45-47, 1972-1974, pp. 475 ss. y F. Villar, Estudios de celtibérico y de toponimia prerromana, Salamanca, 1995.

Se da el caso de que en el territorio ocupado por un mismo pueblo hay algunas ciudades que acuñaron monedas. Asi Bursau y Turiaso en el área lusona; Kaskaita, Kalakoricos en la zona celtibérica próxima al Ebro y Varacos, Teitiacos y Karalus en la zona berona. La ubicación de estas cecas en unas o en otras ciudades, no es totalmente aleatoria. Parece que hubo una planificación territorial de las cecas existentes de tal manera que hay ciudades que acuñaron monedas de plata y bronce, otras que sólo emitieron monedas de bronce y otras que no acuñaron, ver J. J. SAYAS ABENGOCHEA, "Conquista y colonización del Valle del Ebro en época tardorepublicana y Principadon en E. ORTIz DE URBINA y J. Santos (eds.), Revisiones de Historia Antigua 1I: Teoria y práctica del ordenamiento municipal en Hispania, Vitoria-Gasteiz, 1996, p. 71.

Entre las comunidades calificadas posteriormente de vasconas que emitieron monedas con signario ibérico se encuentran Alaun, laka y Setia. La comunidad de Allavona emitió ejemplares con la leyenda Alaun. La ceca pertenece al grupo de los Tres Delfines que tuvo una fuerte implantación en territorio sedetano, ver $A$. Dominguez, Las cecas o. c. pp. 52-55. J. Untermann, Monumenta Linguarum Hispanicorum, Wiesbaden, 1975, pp. 199-200 pone en relación la leyenda de esta ceca con el texto alauniltirte recogido en el grafito de Cogull. Llama la atención en lo que él considera que es un sufijo en - $n$ y que J. Caro Baroja (Sobre la lengua vasca, San Sebastián, 1988, p. 159) relaciona con el morfema vasco de locativo-n, que como fenómeno explicativo se extendia a los rótulos monetales de Bentian, Bolskan y Barscunes, ver al respecto J. DE Hoz, «El poblamiento antiguo de los Pirineos desde el punto de vista lingüistico", en J. BerTRÁN PETTT y E. VIVES (eds.), Muntanyes y població. El passat dels Pirineus des d una perspectiva multidisciplinària, Andorra, pp. $274-275$.

Las cecas de laka y Sekia, que acuñan monedas de plata y bronce respectivamente, se integran estilisticamente en la tipología impuesta por la ceca Bolskan, constituyendo el grupo denominado convencionalmente "grupo Pirenaico o de la Suessetania". Para el análisis y distribución de las monedas de esas cecas, ver A. Dominguez, Las cecas o. c. pp. 135-138 y pp. 157-164 respectivamente. Pese a los rasgos lingüísticos que vinculan el nombre de la comunidad Segia con la raíz celta "sego, victoria, sus monedas no ofrecen semejanzas tipológicas con la monedas celtibéricas, sino que sus formas están muy próximas a los modelos de la ceca de Bolskan, tanto por los tipos suministrados, como por la marca On del anverso.

37 Próximas a la comarca considerada, pero en tierras no pertenecerán al territorio vascón, se encuentran las cecas Karalus, Caraues y Turiasu. De la ceca de Karalus se dispone de un único ejemplar, un as semiuncial hallado en Brihuega (Guadalajara). Las caracteristicas físicas y estilísticas de esta moneda la acercan al grupo de las cecas celtibéricas. Estas razones y el factor etimológico han llevado, sin razones decisivas, a situar esta ceca en la ciudad riojana de Grávalos.

La ceca de Caraues pertenece a la comunidad de Karauis, una ciudad que Apiano (Iber., 43) presenta como aliada de Roma y que Graco liberó del asedio celtibérico. El ltinerario de Antonino la sitúa a 18 millas de Tarazona y a 37 de Zaragoza. Se piensa que hay que situarla en la zona Magallón-Mallén-Gallur. M. BELTRAN LLOPIS, “Problemas cronológicos en torno a la Celtiberia aragonesa», I Simpo. celtib., Zaragoza, 1987, pág. 36; A. Dominguez, "La moneda celtibérica» en Los celtíberos, Zaragoza, 1988, pág. 168 mantienen su ubicación en Magallón. Pero la ubicación de la ceca en la comarca de Gallur queda reforzada, si la abreviación Kal/Gal que aparece en el anverso de los ases se pone en relación con el grupo étnico de galos. Con ello, además, el nombre actual mantiene una aparente semejanza homofónica.

La ceca de Bursau sólo acuñó ases y divisores en pequeña proporción, ver A. Dominguez, Las cecas o. c. pp. 100106. Esta ciudad es la misma que la comunidad de los bursaones mencionados en la Periocha 91 de Tito Livio. Plinio (III, 3, 24) la recuerda como ciudad estipendiaria. Se identifica con la localidad de Boria, sin problemas serios. La ceca de Turiasu acuñó gran cantidad de moneda, sobre todo de plata. Esta ciudad indígena y luego romana, mencionada con relativa frecuencia en los fuentes literarias, se identifica con la ciudad de Tarazona. Ver sobre sus monedas A. Dominguez, Las cecas o. c. pp. 172-185 y J. UntermanN, Monumenta Linguarum 0. c. pp. $260-263$. 
8. Es evidente que durante la segunda mitad del siglo II a. C. las diferencias y el contraste entre la zona del valle del Ebro y las partes central y norteña de Navarra fue inmenso. Lo que se constata en la zona de la Navarra Media son pequeños poblados, algunos siguiendo un esquema de jerarquización. Por el contrario, la comarca de Tudela y tierras adyacentes contaban con un amplio ramillete de ciudades. Al oeste estaba la berona Vareia (Logroño), luego Calagurris, Gracchurris y Cascantum, calificadas posteriormente como vasconas. Seguian las lusonas Bursau (Borja), Turiasu (Tarazona), Caraues - sin identificación precisa, probablemente en algún lugar en el sector Magallón-Mallén-Gallur -, y luego Alaun (Alagón, Zaragoza), la más oriental, consignada posteriormente como vascona. En el sector oriental, cabe mencionar Setia (Ejea de los Caballeros, Zaragoza) y laka (Jaca), también consideradas luego como vasconas. Eran comunidades locales, algunas de ellas de origen anterior a la presencia romana, que actuaban por cuenta propia, sin verse condicionadas por lo general por el resto de ciudades, ni por el grupo étnico. De hecho disputaban entre ellas por cuestiones de límites, pues las fronteras inter civitates no fueron estáticas, sino dinámicas, al menos hasta que Roma consolidó su dominio. Las ciudades peleaban por cuestión de los límites. La Tabula Contrebiensis del año 87 a. C., fecha posterior a la que consideramos, recoge un pleito entre ciudades y deja entrever que la civitas Sosinestana dependía de Alaun, posteriormente vascona.

8.1. Durante el período que se extiende desde el año 133 al 82 a. C. la zona gozó de paz y tranquilidad. Los fermentos de la romanización, libres de los estigmas de la guerra y de la conquista hicieron notables progresos. Pero la guerra social en Italia y su continuación en Hispania con la guerra sertoriana supuso para la zona una gran convulsión. La lucha de Mario y Sila provocó la venida a Hispania de partidarios de ambos bandos. Al mismo tiempo los soldados hispanos que se encontraban sirviendo en los ejércitos romanos palparon directamente la gravedad de la situación romana y se vieron implicados en ella. Así sucedió con los componentes de la turma salluitana, provenientes de diversas comunidades indígenas, entre ellas Setia, que recibieron la ciudadanía romana por decisión del general Gneo Pompeyo, por su acto de valor en el asalto de Áscoli, ${ }^{38}$. En Hispania, ambos bandos buscaron reforzar los viejos lazos de clientelismo e intentaron crear otros nuevos. Disponer de este tipo de clientes beneficiaba a los bandos enfrentados, pero también a los indígenas. Los clientes nativos pertenecian por lo general a la clase dirigente de comunidades que se encontraban en pleno desarrollo y transformación. Tenían en ellas un peso específico y podian

${ }^{38}$ Este interesante documento ha sido objeto de una cuidada edición, completada con el estudio de los problemas jurídicos, cronológicos y lingüísticos a los que da pie el texto. Ver al respecto N. CRITINI, L'epigrafe dí Asculum di Gn Pompeo Strabone, Milán, 1970; H.B. Mattingly,"The consilium of Cn. Pompeius Strabo in 89 B.C.", Athenaeum, 53,1975, p.262 y ss. El estudio del documento en su contexto histórico puede verse en J. M. Roldán, “El bronce de Ascoli en su contexto histórico" en Actas sobre Epigrafia hispánica de época romano-republicana, Zaragoza,1986, pp.115-135. 
encauzar hacia uno de los bandos las simpatías de toda la comunidad. Las frecuentes estancias de Sertorio en la zona acrecentaron las simpatías hacia él de algunas comunidades indígenas. Ese fue el caso de Osca y Calagurris que se revelaron como partidarias contumaces de Sertorio. Por su parte, Pompeyo contrarrestó la política sertoriana de acercamiento a los nativos intensificando sus propias clientelas en el Valle del Ebro, donde ya disponia de terreno abonado en aquellas comunidades participantes en la turma Salluitana, cuyos componentes fueron gratificados por el padre de Pompeyo con la ciudadania romana.

8.2. De esta manera, la zona se convirtió en un amplio campo de bataIla donde los contendientes pelearon con inusitada crueldad ${ }^{39}$. Y en medio de ese mundo inaudito y perturbado, las destrucciones padecidas por algunas comunidades de la orilla derecha del Ebro contrastan con los impulsos urbanizadores y el empuje económico que recibieron algunos pequeños poblados del territorio vascón. Las tropas de Pompeyo, retiradas a tierras vasconas para invernar y para mantener expeditas las rutas con las Galias, tomaron el pulso a todo el territorio vascón y sacaron de ello una reflexión étnico-geográfica por la que tomaron conciencia de que no todos los poblados, especialmente los situados más al norte, reunian las condiciones necesarias para asimilar los cambios. Sucedía lo mismo con algunos poblados de la Navarra Media. Sin embargo, el pequeño poblado situado en la actual Pamplona, cuyo nombre indígena, si lo tuvo, se desconoce, se transformó en Pompeyopolis, ciudad de Pompeyo como dice el geógrafo griego Estrabón, o en Pompoelo, glosa vasca de Pompeyopolis, con un segundo elemento -el(n), ilu(n) antecedentes del vasco iri, irum ciudad. Pompoelo significa, por tanto, lo mismo que Pompeyopolis, ciudad de Pompeyo, pero con composición vasca. $Y$ por razones similares y también en esos momentos, los poblados de la Edad del Hierro de Andelos (Muruzabal de Andión) y de Cara (Santacara) se transformaron en ciudades, como se desprende de los testimonios arqueológicos estudiados por $\mathrm{M}^{\mathrm{a}}$ A. Mezquiriz ${ }^{40}$.

8.3. Frente a la promoción y desarrolló que se aprecia en tierras interiores vasconas, las tierras de la comarca de Tudela y zonas adyacentes padecie-

39 Con relación a la incidencia que las guerras sertorianas y civiles tuvieron en las comunidades del valle del Ebro y el juego desempeñado por las clientelas, ver N. Dupré, "La place de la vallée de l'Ebre dans I'Espagne romaine. Recherches de géographie historique», MCV 8, 1973, pp. 133-175; J. M. Roddaz,"Guerres civiles et romanisation dans la valiée de l'Ebre”, REA., 1986, pp.317-338; L. Amela Valverde,"El desarrollo de la clientela pompeyana en Hispania", Studia Histórica 7, 1989, pp. 105-117.

40 J. Gorrochategui, “Los Pirineos ... o. c. p. 232 considera que el topónimo Pompaelo, y posiblemente también Andelos, presentan un segundo elemento -elo que seria el antecedente del vasco iri, irun, ciudad. Los datos arqueológicos ayudan en cierta manera a colocar la planificación urbanística de Pompaelo, Andelos y Cara durante y asociada a los conflictos sertorianos, ver $M^{a}$ A. Mezquiriz, La excavación estratigráfica de Pompaelo I. Campaña de 1956, Pamplona, 1958; Pompaelo II, Pamplona, 1978; "Materiales procedentes del yacimiento romano de Andión», P. V., 100-101, 1960, pp. 210-214; “Cerámica prerromana hallada en las excavaciones de Santacara (Navarra)", XIV Congreso Arqueológico Nacional, Zaragoza, 1977 , pp. 599-604 
ron la violencia y las destrucciones provocadas por ambos bandos contendientes ${ }^{41}$. Pero ello abrió el camino a nuevos cambios y transformaciones. Por vez primera y a propósito de eso combates las fuentes históricas dan a conocer que el territorio (ager) de los Vascones se extendían también por la orilla derecha del Ebro, al menos en el sector que desde Calagurris - fiel a Sertorio hasta su destrucción por las tropas pompeyanas-, llevaba a la frontera de los berones. Pero en esa misma línea del Ebro serán las tropas sertorianas las que causen estragos. Los bursaones, próximos a territorio vascón, y los cascantinos y graccurritanos, valorados como vascones por fuentes posteriores, contemplaron como el ejército sertoriano atacaba sus territorios y destruía sus cosechas. Un fragmento del libro 91 de Tito Livio nos informa que durante las guerras sertorianas, posiblemente en el año 75 a. C., Sertorio marchó contra los territorios de los bursaones (posiblemente Borja), de los cascantinos y de los gracurritanos y les asoló las cosechas y se encaminó hacia Calagurris Nasica, ciudad de aliados (sociorum urbem)... y a través del territorio de los vascones acampó en los confines de los berones ${ }^{42}$.

41 Sobre los alineamientos de las ciudades de la zona al lado de uno u otro de los contendientes, ver J. J. SAYAs ABengochea, “Indoeuropeos y vascones en territorio vascón", Studia Palaeohispanica. Actas del IV coloquio sobre lenguas y culturas paleohispánicas, Victoriaco Vasconum, 1987, pp.409-410.

42 Tito Livio frag, 91, A. C. Schlesinger, Summaries, fragments and obsequents of Livius, Loeb Classical Library, XIV, Harvard 1967, pp. 186-195. 